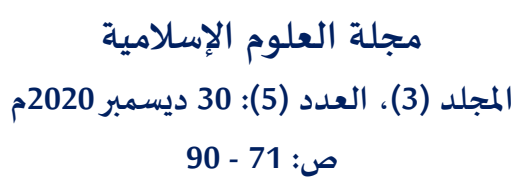

ص: 71 - 90

\title{
Analyzing the content of some Islamic advocacy sites on the Internet - a descriptive study: Islam Today website, the preaching diary website, and the Dar AI Salam site for the Islamic Call
}

\author{
Hashim Ahmed Alhamami \\ Department of Journalism and Media || Arab Open University
}

\begin{abstract}
The aim of this research is to shed light on the contents of the Da wah sites on the Internet and to achieve the goals of the research, a descriptive-analytical approach has been used by analyzing the content of a number of Da wah websites. The study sample consisted of three Da wah sites (Islam Today, the Da wah website), And Dar Al Salam for Islamic Da wah), which is the most widespread on the Internet, and the analysis of the questionnaire, which consisted of (146) participants.

Among the most important findings of the research is that the Islamic Da wah sites include many windows, articles, and books that serve the Islamic Da wa and contribute effectively to informing non-Muslims about the image of Islam and creating a positive image and impressions toward the Islamic religion for the browser. The da'wah sites also provided the teachings of the Islamic religion in a way that could be easily understood by non-Muslims, educating Muslims who wish to agree on matters of their religion, increasing their awareness and information about the Islamic religion, and wanting to take fatwas on many topics that concern them. Moreover, the research found that the target audience of the Islamic Da wah sites were those who want to get to know Islam from the non-Muslim and Muslims, and the general Islamic audience who wants to agree on matters of their religion, and the individuals and institutions working in the field of Islamic Da wa. The research also concluded that one of the most important goals that most Da wah sites aim to achieve is to present a message to Muslims and to invite non-Muslims, that is, they have two informational and advocacy messages.

Finally, the research found that a strong degree of agreement for the participants, the participants 'agreement on the clarity of the goals used by the Da wah sites (Islam Today website, the Da'wah Calendar website, and the Dar es Salaam site for Islamic Da wah) via the Internet on the contents of the Islamic Da 'wah, and to a degree of good agreement between the members of the sample for each of the mechanisms The use of the noble hadiths in the propaganda sites via the Internet, methods, and methods of reasoning and fatwas and topics used by the prophetic sites via the Internet, and the values that are concerned with addressing the propaganda sites.
\end{abstract}

Keywords: Islamic Da wah sites, the Internet, the contents of Islamic Da`wah sites, Islam Today website, Da wah Calendar website, Dar Al Salam website for Islamic Da`wah.

$$
\text { تحليل محتوى بعض المواقع الدعوية الإسلامية على شبكة الإنترنت- دراسة وصفية: }
$$


الملخص: هدفت هذه الدراسة إلى تسليط الضيوء على مضامين المواقع الدعوية على شبكة الإنترنت، ولتحقيق أهداف البحث تم

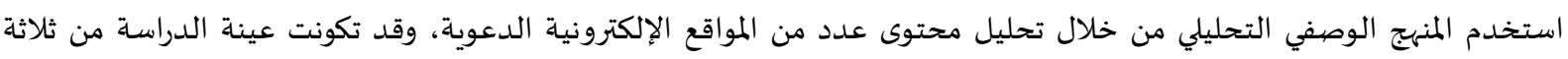

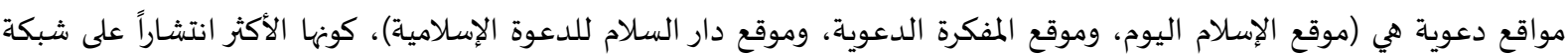
الإنترنت

ومن أهم النتائج التي توصل الهيا البحث أن مواقع الدعوة الإسلامية تتضمن العديد من النوافذ والمقالات والكتب التي تخدم الدعوة

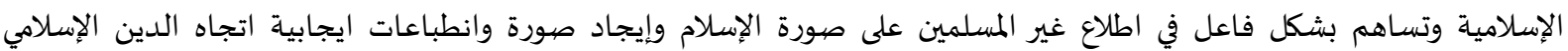

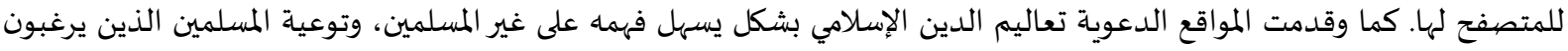

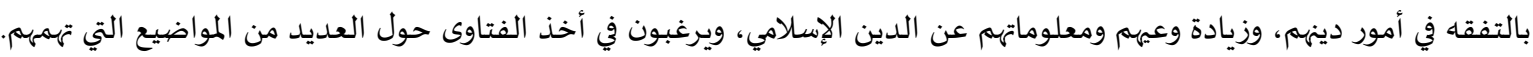

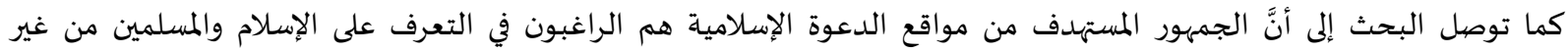

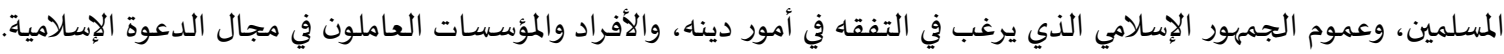

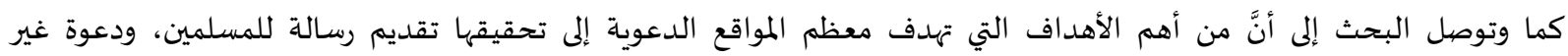

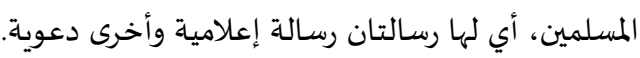

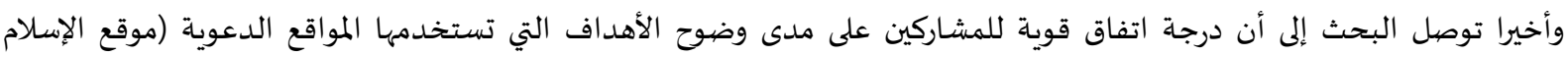

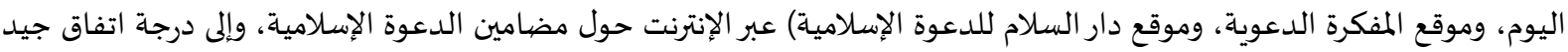

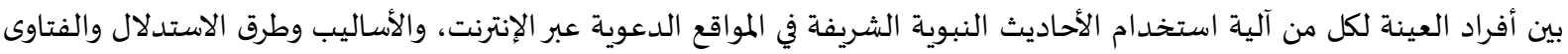
والموضوعات التي تستخدمها المواقع الدعوية عبر الإنترنت، والقيم التي تهتم بمعالجتها المواقع الدعوية.

الكلمات المفتاحية: المواقع الدعوية الإسلامية، الإنترنت، مضامين المواقع الدعوية الإسلامية، موقع الإسلام اليوم، موقع المفكرة الدعوية، موقع دار السلام للدعوة الإسلامية.

المقدمة

يعد الإنترنت أحد أهم مظاهر التطور الحضاري في العصر الحالي نظراً لما يقدمه من ثروات معرفية وعلمية وترفيهية ورياضية في حياتنا اليومية. وعلى الرغم من الجوانب الإيجابية التي يوفرها الإنترنت من حيث الكم الهائل الهئل

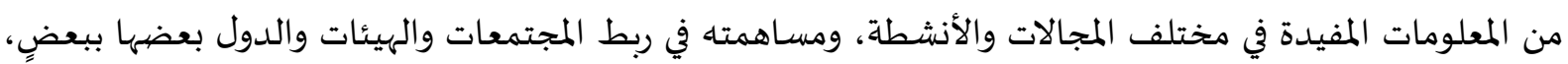

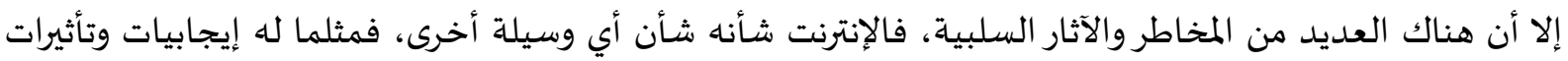

محمودة، فإن له أيضا سلبيات وتأثيرات غير مرغوبة.

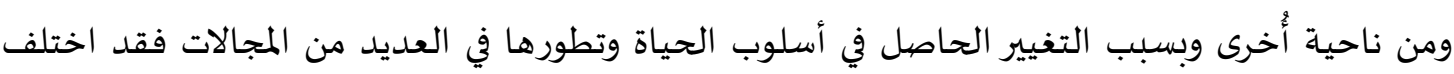

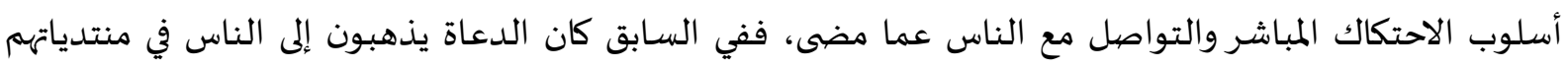

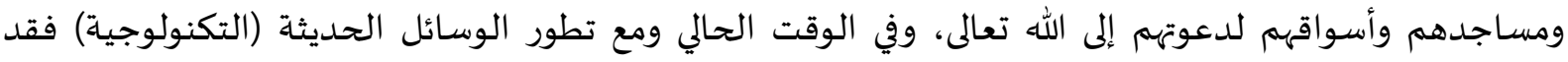

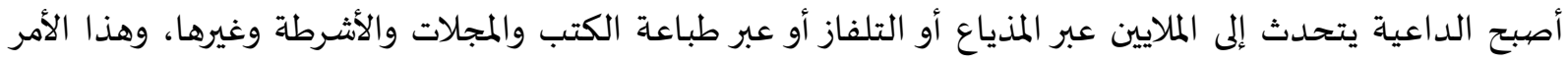

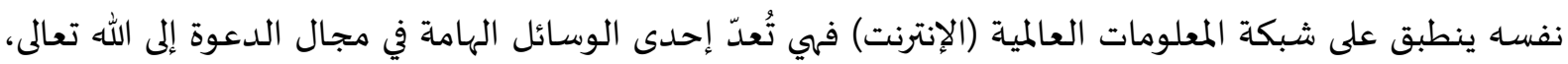

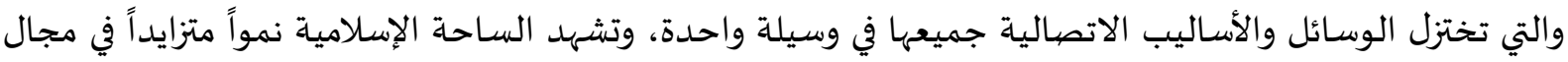

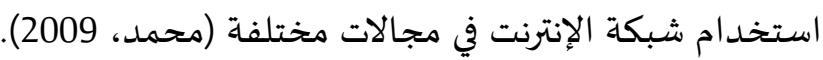

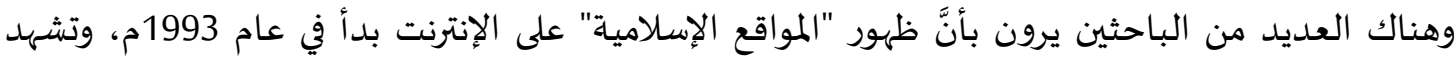

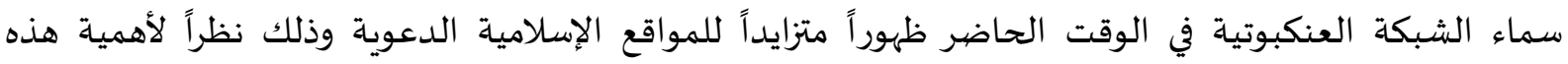
الشبكة في الوصول إلى أعداد كبيرة من الجمهور، وانخفاض التكلفة المادية للدخول على الشبكة واستخداهيها،

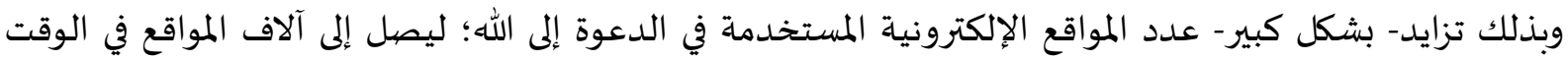

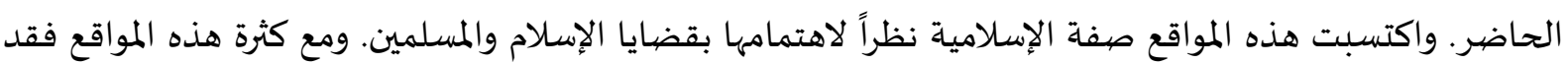


كان لابد من وجود آلية تنظم عمل هذه المواقع، وتسعى لتطويرها وتحسين أدائها وتتعرف على مضامينها (بلال،

وعليه فقد جاءت فكرة هذه الدراسة والتي تسعى إلى التعرف على مضامين المواقع الدعوية على شبكة

المعلومات العالمية الإنترنت، عن طريق تحليلها وصفياً والوصول إلى نتائج تخدم هدف هذه الفه التعرف الدراسة.

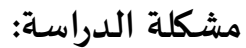

من متطلبات الدعوة في وقتنا الحالي استغلال آخر ما حققته الإنسانية من منجزات حضارية متطورة في العديد من المجالات خاصية في مجال الاتصال والتقنية ونقل المعلومات عبر الإنترنت والذي يُعد من أبرز الوسائل التي من من في في

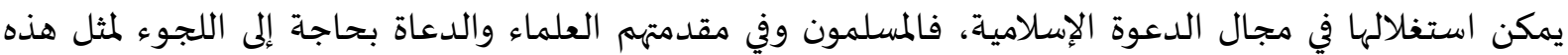
الوسائل من أجل خدمة الإسلام، والتعريف باه، ودعوة غير المسلمين لاعتناق الإسلام، ورد الشبهات عنه من خلال تقديم الإسلام بالصورة الصحيحاة، عبر مواقع الدعوة الإسلامية المختلفة، ومع تطور شبكة الإنترنت وتحولها إلى وسائل إلكترونية وفقاً لمتطلبات العصر، فقد ظهرت العديد من المواقع المتخصصة في نشر الدعوة الإسلامية وعليه فقد جاءت فكرة هذه الدراسة والتي تهدف إلى تحليل مضيمون المواقع الدعوية على شبكة الإنترنت.

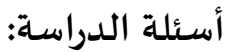

بناء على ما سبق؛ تتحدد مشكلة الدراسة في الأسئلة التالية:

1. ما أهم الأهداف التي تسعى المواقع الدعوية لتحقيقها؟

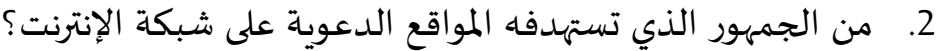

3. ما مدى وضوح الأهداف التي تستخدمها المواقع الدعوية عبر الإنترنت؟

4. ما آلية توظيف الأحاديث النبوية الشريفة في المواقع الدعوية عبر الإنترنت؟

5. ما القيم التي تهتم بمعالجتها المواقع الدعوية عبر الإنترنت؟ لماتع

6. ما الأساليب وطرق الاستدلال والفتاوى والموضوعات التي تستخدمها المواقع الدعوية عبر الإنترنت؟

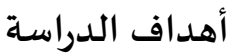

تتحدد أهداف البحث فيما يلي:

1. التعرف على الأهداف المختلفة التي تسعى المواقع الدعوية لتحقيقها.

2. التعرف على الجمهور الذي تستهدفه المواقع الدعوية على شبكة الإنترنت.

3. التعرف على آلية توظيف الأحاديث النبوية الشريفة المستخدمة في المواقع الدعوية عبر الإنترنت

4. التعريف على القيم التي تهتم بمعالجتها المواقع الدعوية عبر الإنترنت.

5. التعرف على الأساليب وطرق الاستدلال والفتاوى والموضوعات التي تستخدمها المواقع الدعوية عبر الإنترنت

أهمية الدراسة

تكمن أهمية الدراسة فيما يلي:

أنها تسهم في التعريف بالمواقع الدعوية، على شبكة الإنترنت من حيث الشكل والمضمون والجمهور، وتقييم نقاط الضعف والقوة فيها وفي مضامين هذه المواقع، بما يلفت نظر القائمين عليها إلى ضرورة تنميتها وتطويرها. 
وتلفت الدراسة أيضاً نظر الدعاة إلى الإنترنت والذي يُعد من أكثر من طاقته

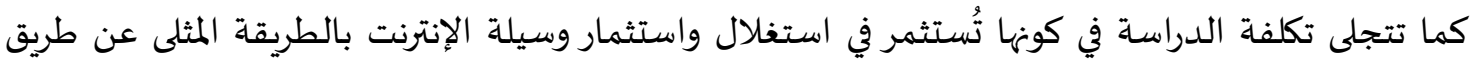
تحليل مضامين المواقع الدعوية على شبكة الإنترنت من تشخيصها وإبداء خدماتها وفقاً لنتائج الدراسـة.

$$
\text { 2- الإطار النظري والدراسـات السـابقة }
$$

سيتناول هذا الجزء من البحث الحديث عن الإنترنت وفوائده، كما وسيتم التحدث عن الدعوة والمواقع الدعوية، وأخيرا سيتم استعراض عدد من الدراسات السابقة المتعلقة بموضوع البحث.

بدأت الثورة الحقيقية لشبكة الإنترنت في عام 1993م والتي تم فيها اختراع الشبكة العنكبوتية وتعرف شبكة الإنترنت على أهها شبكة ضخمة من أجهزة الحاسب المرتبطة ببعضها البعض والمنتشرة حول العالم (بلال،

ومن ناحية أُخرى يرى (عبد الرزاق،2015) أن مفهوم شبكة الإنترنت هو عبارة عن شبكة تتكون من مجموعة الحاسبات الآلية التي ترتبط ببعضها البعض عبرَ خطوط الهاتف أو من خلال الأقمار الصناعية، وتمتد عبر العالم حتى تكون شبكة كبيرة من أجل نقل المعلومات بحيث يمكن للمستخدم الدخول إلى أي منها في أي وقت ومن أي مكان يتواجد فياه حتى ولو كان في الفضاء. كما وتعتبر الإنترنت كوسيط للاتصال بالآخرين، وتكنولوجيا وسيطة يكون الهدف منها التواصل وتحسين العلاقات الاجتماعية للفرد، وهي المكان الذي تنشأ منه علاقات اجتماعية

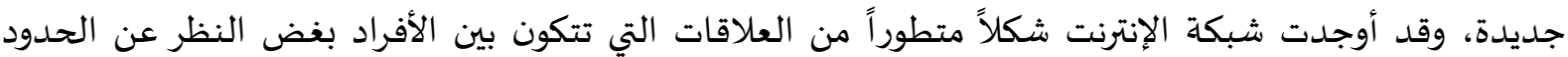
المكانية والزمانية وتسمح بتحقيق تفاعل وتواصل اجتماعي. والإنترنت عبارة عن شبكة حاسوبية عملاقة تتكون من مجموعة من الشبكات الصغيرة، بحيث يمكن لأي شخص متصل بالإنترنت أن يتجول في هذه الشبكة وأن يحصل على المعلومات كافة في أي مكان من العالم وعليه

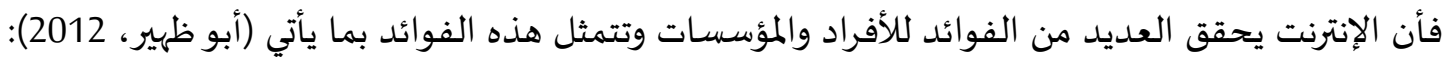
خدمة البريد الإلكتروني بحيث يمكن مراسلة أي شخص في العالم، ويتميز بخاصيتين مهمتين: السرعة وقلة التكلفة. للباحثين والطلاب: حيث تمكنهم الإنترنت من الاطلاع على المستجدات في الأبحاث والمعلومات التي تهم الباحث في تخصصه من المواقع والنشرات والدوريات. الأخبار: يمكن الاطلاع على الأخبار بأنواعها حول العالم عن طريق مواقع وكالات الأنباء والمواقع الإخبارية التي تقوم بنشر الأخبار أولاً بأول. الاستثمار والتجارة الإلكترونية: حيث يمكن متابعة الأسواق المالية المختلفة والبنوك والتأمين والضرائب

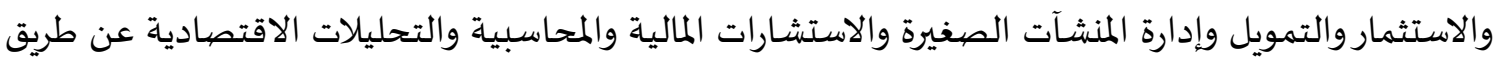
المواقع المخصصية لذلك. التعلم عن بعد، واستخدامها لإعطاء الدروس الافتراضية، بالإضافة إلى استخدام الإنترنت في التواصل مع

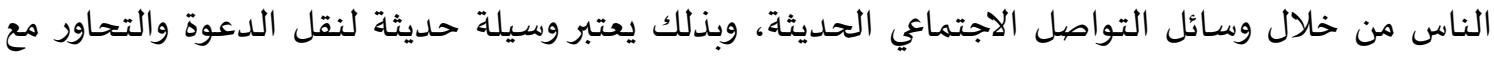
الناس. 
الدعوة إلى الله: حيث انتشرت العديد من المواقع الدعوية، كموقع الإمام عبد العزيز بن باز وموقع الشيخ

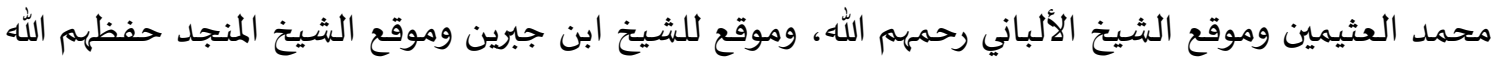

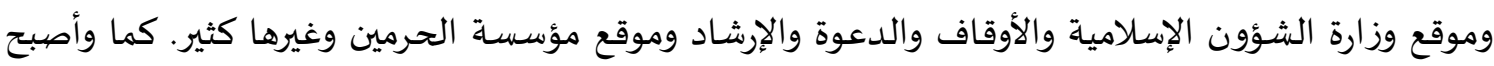

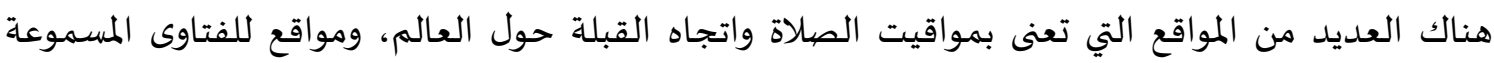

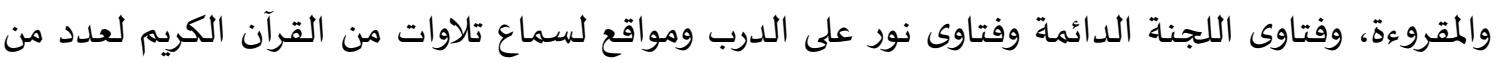

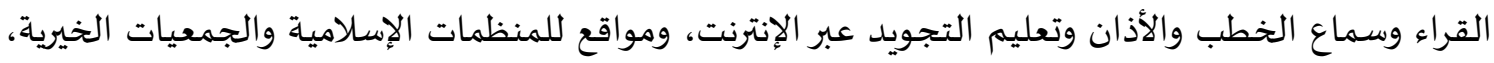

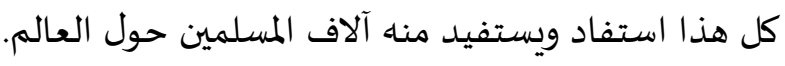

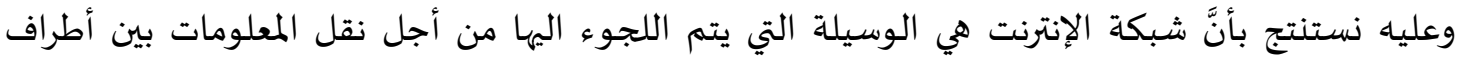

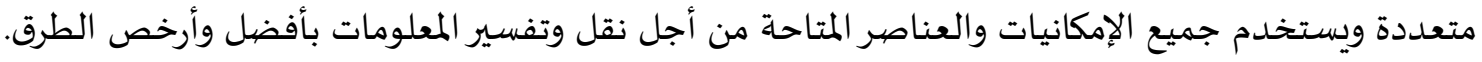

$$
\text { المواقع الدعوية }
$$

أولا- تعريف الدعوة:

مما يجدر الإشارة إليه أن العلماء قد اختلفوا في تعريف علم الدعوة فقد عرفها شيخ الإسلام ابن تيمية بقوله: (الدعوة إلى الله، هي الدعوة إلى الإيمان باه، وبما جاءت باه رسله، بتصديقهيهم فيما أخبروا باه وطاعتهم فيما

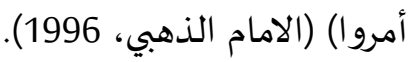
أما بلال (2015) فيرى بأنَّ علم الدعوة هو العلم الذي باه تعرف كافة المحاولات الفنية المتعددة التي تهدف إلى تبليخ الناس الإسلام بما يتضمنه من عقيدة وشريعة وأخلاق.

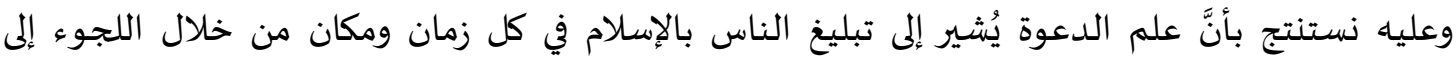
استخدام أساليب ووسائل متنوعة تتناسب مع المدعوين وفقاً لكل عصرئ ومكان.

$$
\text { ثانيا- التعريف بالمواقع الدعوية: }
$$
تُعدّ المواقع الدعوية من أهم الخدمات التي يتم عبرها بث الدعوة إلى الله عبر الإنترنت، وذلك نظراً لأهها

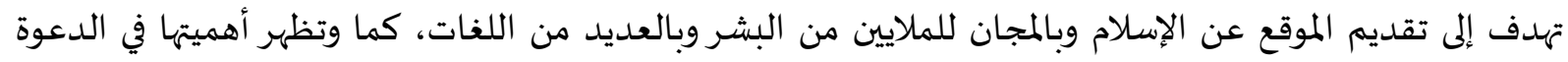

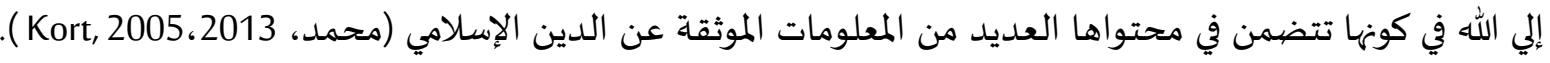

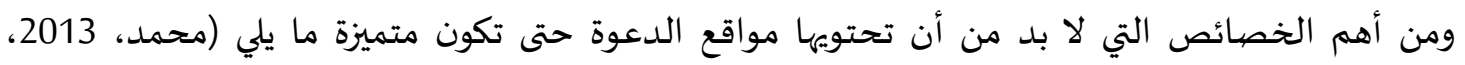

:(Shuriye \& Ajala, 2014

1. جودة المحتوى من حيث المعلومات المنشورة ومدى شمولها وتغطيتها لعديد من المجالات بالإضافة إلى تعدد لغات هذا المحتوى حتى يصل إلى أكبر عدد من مستخدمي الإنترنت. 2. سهولة تصفح الموقع والتنقل بين أجزائه، وهذه السهولة تعتمد بشكل كبير على جودة تنظيم صفحاته

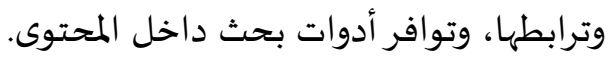

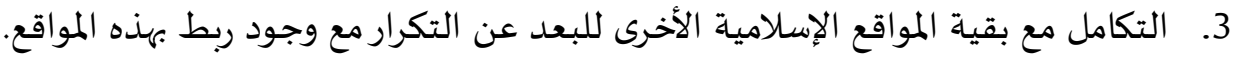
4. البعد عن الخلافات المذهبية والسياسية من أجل تحقيق أكبر قدر من العالمية والانتشار. 5. البعد عن التقليد في تصميم الموقع.

6. الحرص على تطوير الخطاب الدعوى في الموقع بما يتلاءم مع أهمية الدعوة وتصنيفها. 
ومن أهم القواعد التي يتوجب مراعاتها قبل إنشاء الموقع الدعوي أن يتم إعداد نموذج تخطيطي للصفحة

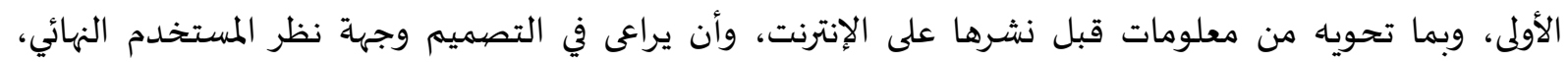

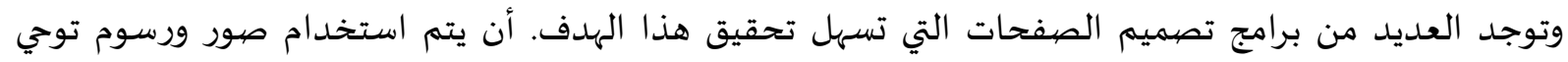

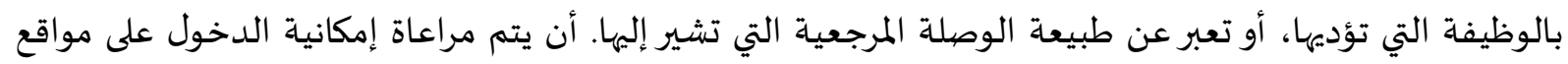

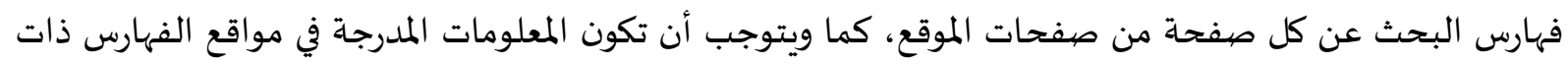

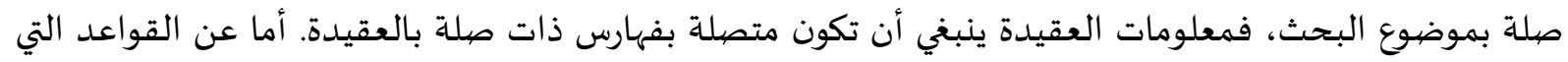

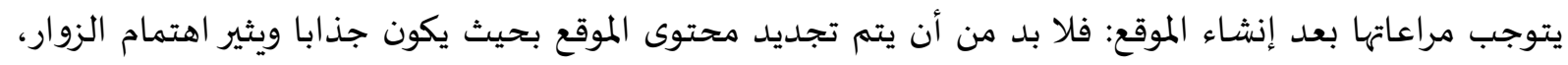

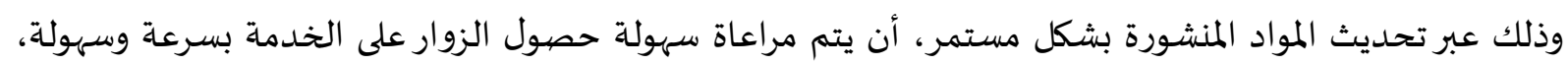

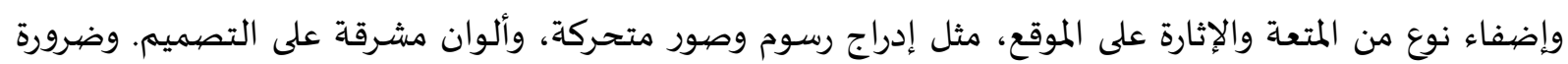

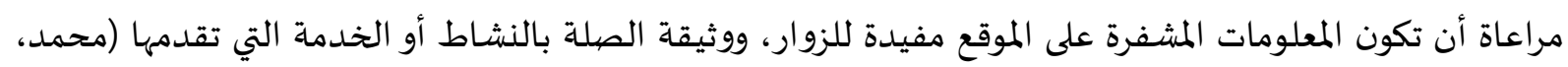

ثانياً- الدراسـات السـابقة

سيتم في هذا الجزء إلقاء الضيوء على الدراسات السابقة التي تناولت متغيرات الدراسة.

دراسة بلال (2015) بعنوان" الدعوة إلى الله تعالى عبر الإنترنت: دراسة تأصيلية وصفية " وهدفت الدراسة إلى التعرف على الإنترنت كوسيلة دعوية مهمة، والتي لم تستثمر في الدعوة إلى الله تعالى، أو أن استثمارها كان اندان

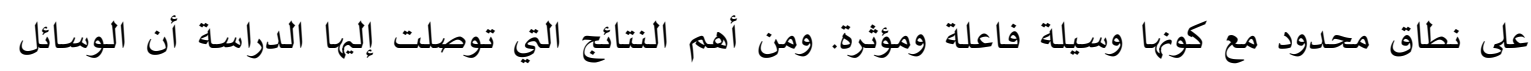

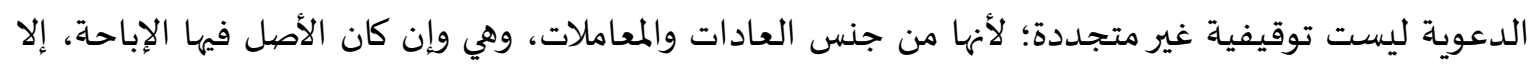

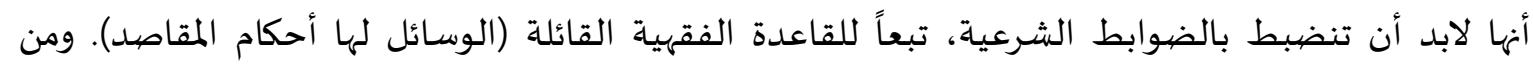

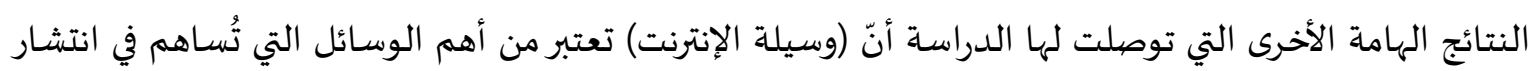

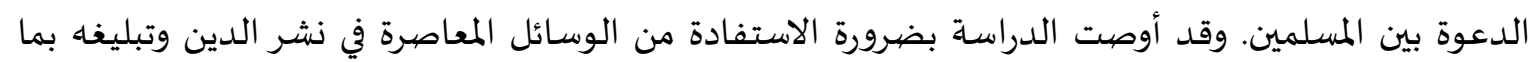
يتناسب مع معطيات العصر. دراسة (محمد،2013) بعنوان "قع الإسلام اليوم Islam Today وإسهامه فى الدعوة إلى الله" وهدفت الدراسة إلى تسليط الضيوء على موقع الإسلام اليوم ومدى مساهمته في الدعوة إلى الله، وقد ركز البحث على اللى ألى أهمية

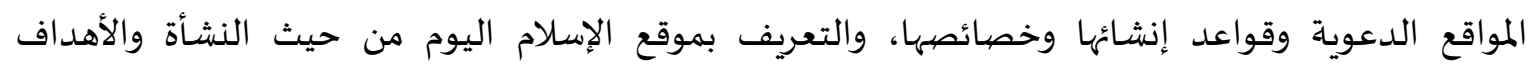

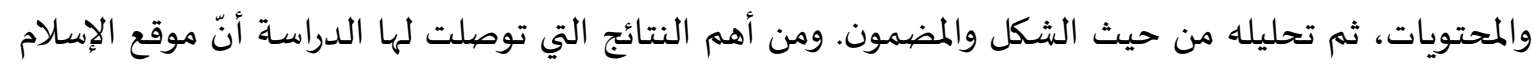

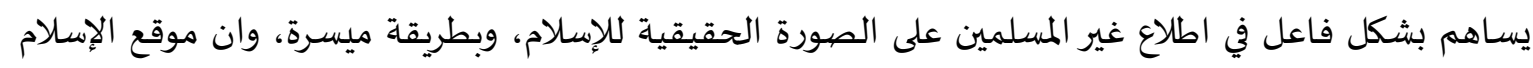
اليوم من المواقع المتميزة من حيث الشكل واعلم المضمون. دراسة (Ismail, et al., 2013) بعنوان “تحليل من منوقع الإنترنت حول استخدام عناصر الوسائط المتعددة

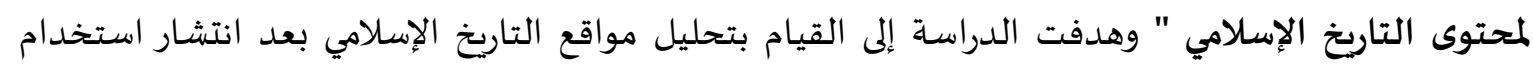

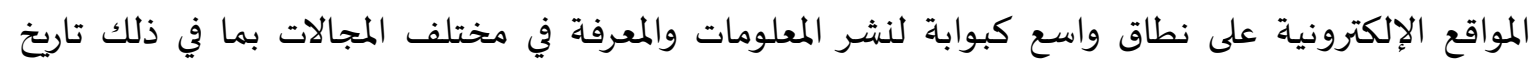

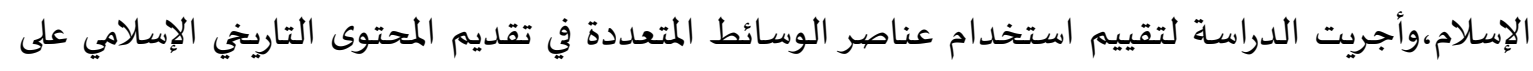
شبكة الإنترنت. تم اختيار ما مجموعاه 50 موقعًا للتارتخ الإسلامي بشكل عشوائي مع الترائل التركيز على المواقع التي تتميز

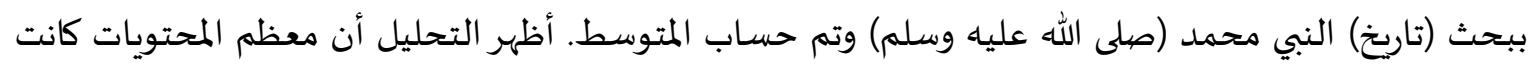

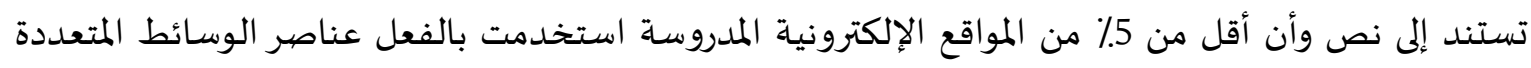


في عرضها. يُعتقد أنه من الضروري اتباع نهج محسّن لتقديم المحتوى التاريخي الإسلامي لأن الأدبيات الموجودة

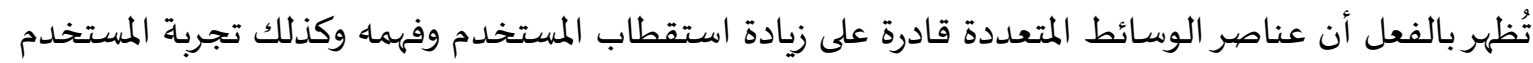

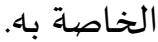

دراسة (Aliyu et al., 2013) بعنون " الميزات المؤثرة في استخدام المواقع الإسلامية: من منظور المستخدم

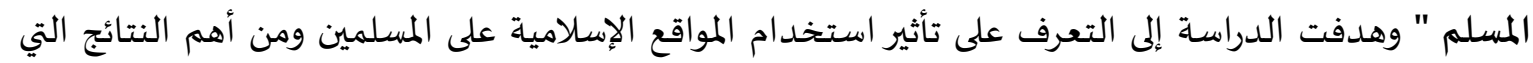

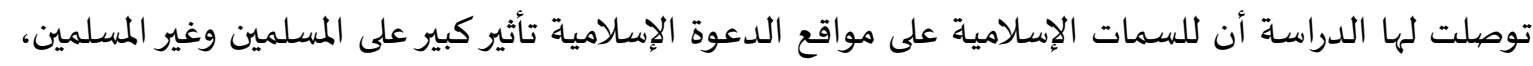

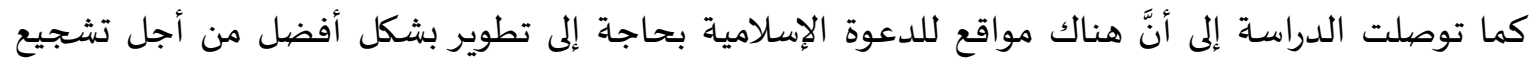
العديد من الافراد إلى استخدام تلك المواقع من أجل التعلم حول التعاليم والممارسات الإسلامية.

تعليق على الدراسات السـابقة:

يتميز البحث الحالي عن الدراسات والأبحاث السابقة أن الدراسات السابقة تناولت موضيوعات مواقع منابع

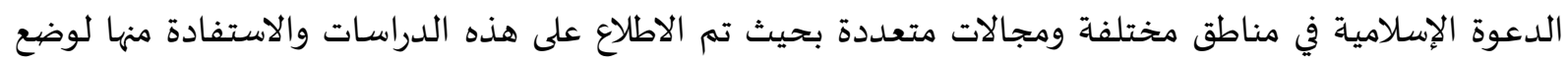

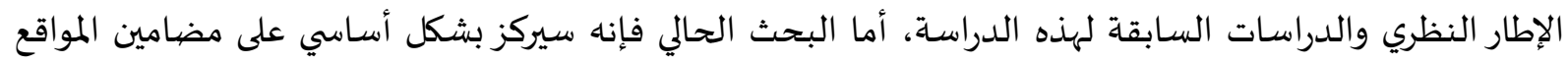

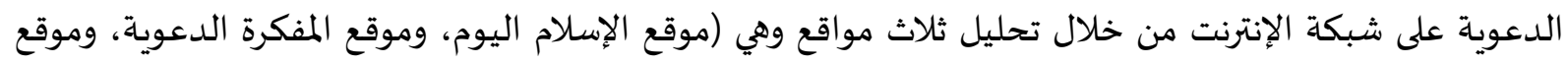

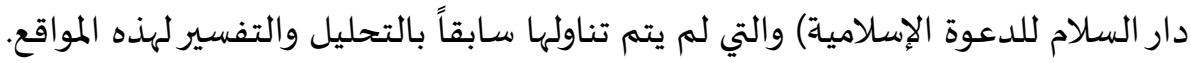

3- منهجية الدراسـة وإجراءاتها.

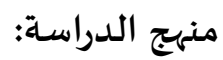

تم استخدام الطرق النوعية والكمية في هذا البحث؛ حيث يتميز المنهج الوصفي بالعديد من المزايا كونه

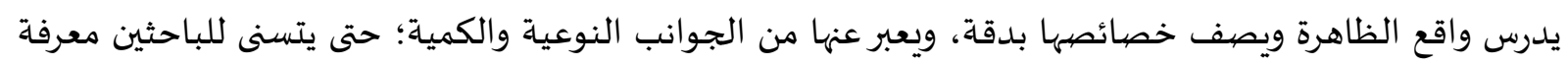

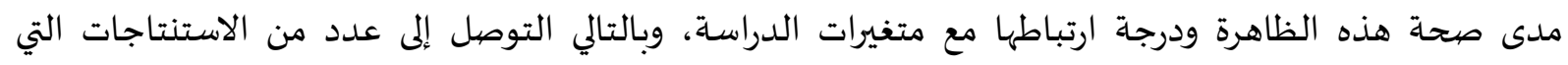
تساعد على فهم الواقع وتنميتاء. كما ويعمل المنهج الوصفي على إجراء دراسة مقارنة للمتغيرات في البحث، وتقييمها وتفسيرها من أجل

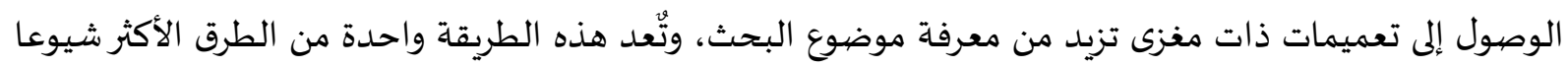
والمستخدمة في مجال العلوم الإنسانية.

$$
\text { مصادر جمع البيانات }
$$

المصيادر الأولية: المصادر التي حصل الباحث من خلالها على البيانات ومعلومات البحث هي من خلال معالجة

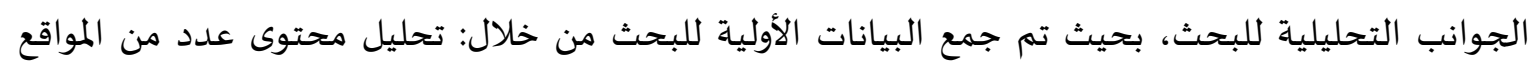

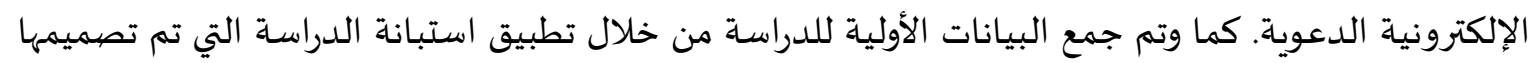

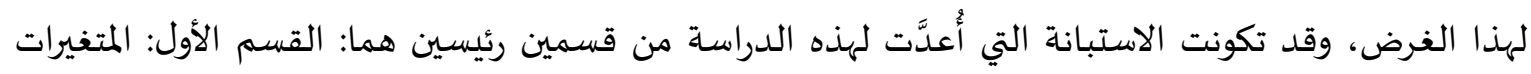

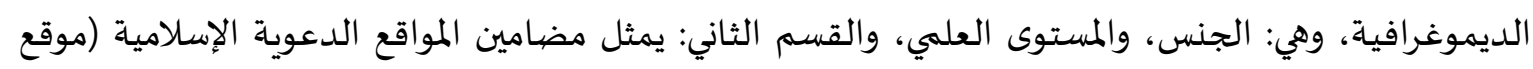

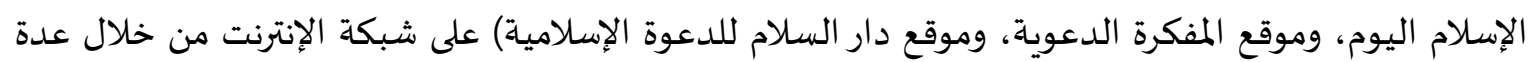
أبعاد، وتم تصميمهما بالاعتماد على الدراسـات السابقة. 
المصادر الثانوية: وقد تم الحصول على بيانات البحث الأولية من خلال إجراء مراجعة للكتب والدوريات

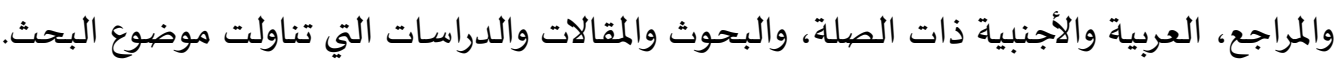

مجتمع البحث وعينته

يتكون مجتمع البحث لتحليل المحتوى على عدد من المواقع الدعوية الإسلامية، ونظراً لصعوبة حصر

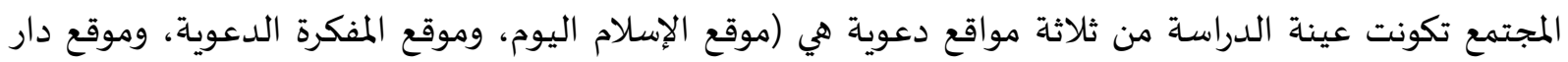
السلام للدعوة الإسلامية). أما فيما يتعلق بمجتمع البحث للاستبانة فإن المجتمع يتكون من جميع الجمهور الذي يتابع هذه المواقع الدعوية (موقع الإسلام اليوم، وموقع المفكرة الدعوية، وموقع دار السلام للدعوة الإسلامية) من جميع الدول، وخلال

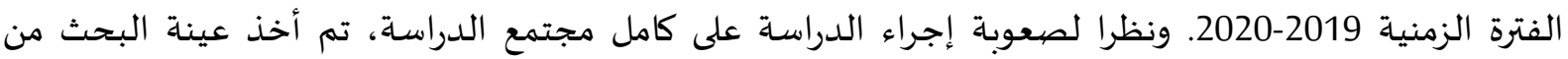

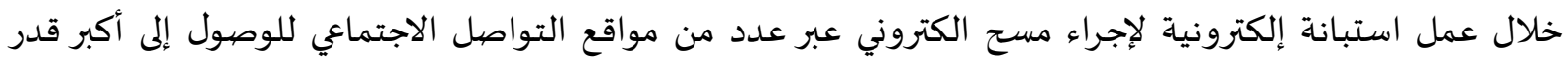

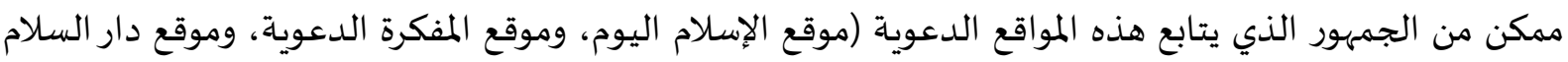

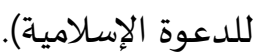
وقد بلغت عينة البحث النهائية التي تم تحليلها (146) من المستجيبين للاستبانة. والجدول رقم (1) يوضح

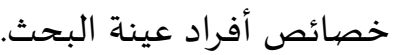

الجدول (1): خصيائص أفراد عينة البحث

\begin{tabular}{|c|c|c|c|c|}
\hline النسبة المئوية\%\% & التكرار & الفئة & المتغير & الرقم \\
\hline$\% 54.1$ & 79 & ذكر & \multirow{2}{*}{ الجنس } & \multirow{2}{*}{1} \\
\hline$\% 44.9$ & 67 & أنثى & & \\
\hline$\% 100$ & 146 & \multicolumn{3}{|c|}{ المجموع } \\
\hline \%17.8 & 26 & ثانوي & \multirow{4}{*}{ المستوى التعليمي } & \multirow{4}{*}{2} \\
\hline$\% 29.5$ & 43 & دبلوم & & \\
\hline \%30.1 & 44 & جامعي & & \\
\hline$\% 22.6$ & 33 & اخرى & & \\
\hline$\% 100$ & 146 & \multicolumn{3}{|c|}{ المجموع } \\
\hline
\end{tabular}

أسـاليب المعالجة الإحصيائية

لتحقيق أهداف الدراسة تم استخدام برنامج ال (SPSS) الرزمة الإحصائية للعلوم الاجتماعية لتحليل

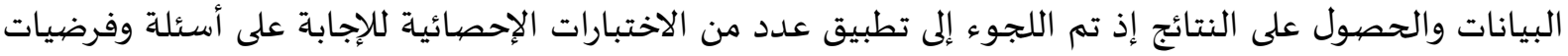

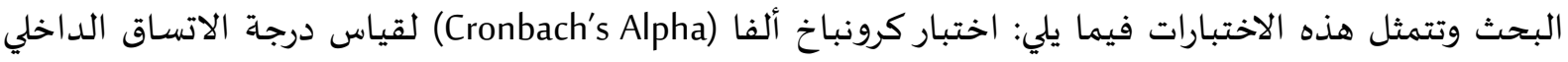

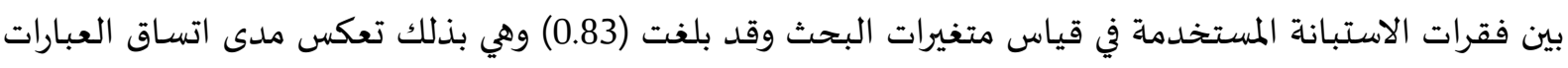

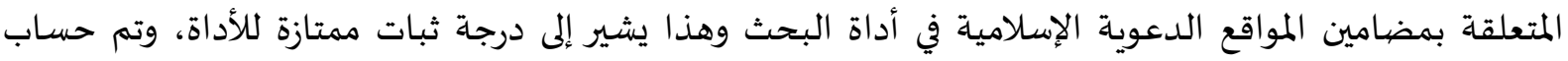

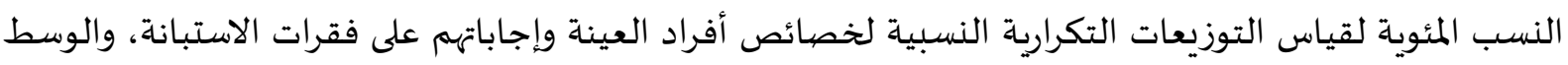
الحسابي لقياس متوسط إجابات المبحوثين على فقرات الاستبانة، والانحراف المعياري لقياس مدى تشتت الإجابات 
عن قيم وسطها الحسابي، كما وتم تحليل محتوى لعدد من المواقع الدعوية الإسلامية والتي تتمثل فيما يلي (موقع الإسلام اليوم، وموقع المفكرة الدعوية، وموقع دار السلام للدعوة الإسلامية).

4- عرض نتائج الدراسـة ومناقشتها. سيتم في هذا القسم تحليل لأهم المواقع الدعوية على شبكة الإنترنت من خلال القيام بتحليل محتوى لعدد من المواقع الدعوية الإسلامية والتي تتمثل فيما يلي (موقع الإسلام اليوم، وموقع المفكرة الدعوية، وموقع دار السلام

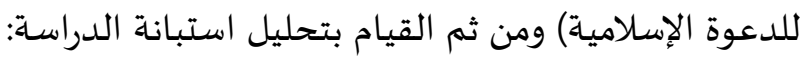

أولاً تحليل محتوى لعدد من المواقع الدعوية الإسلامية والتي تتمثل فيما يلي (موقع الإسلام اليوم، وموقع المفكرة الدعوية، وموقع دار السلام للدعوة الإسلامية): سيتم في هذا القسم تحليل محتوى المواقع الإسلامية وفقاً لمحتواها وأهدافها المواقع الدعوية الإسلامية كما

الفرع الأول: موقع الإسلام اليوم وهو موقع من المواقع الرائدة في مجال الدعوة، ويهدف بشكل أساسي إلى ترسيخ العقيدة الصحيحة عبر

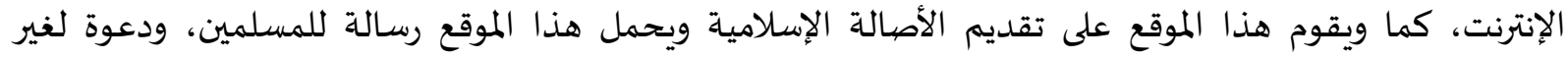
المسلمين، ويهدف إلى ترسيخ العقيدة بطريقة صحيحة في قلوب المسلمين ويراعي هذا الموقع التجديد والتنويع وقوة

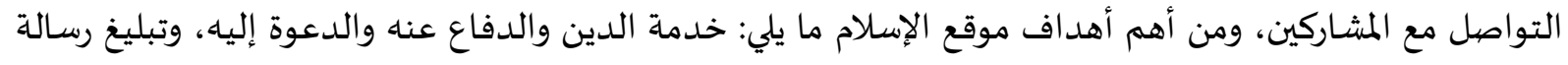

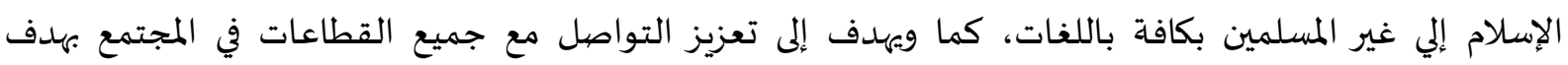

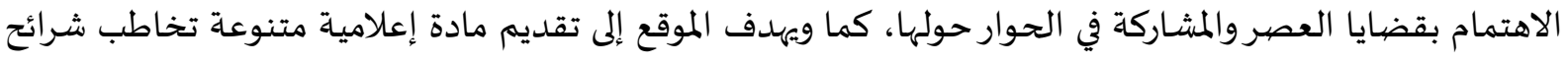

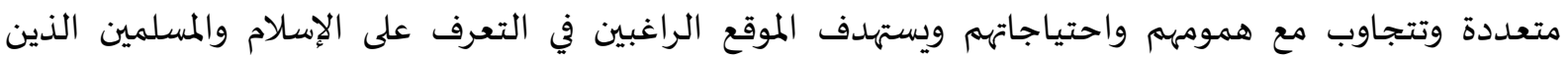

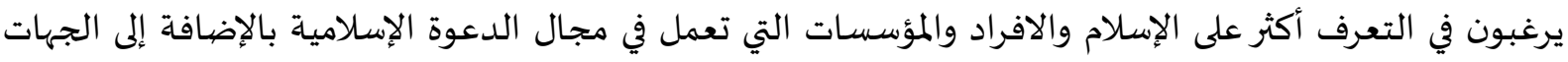

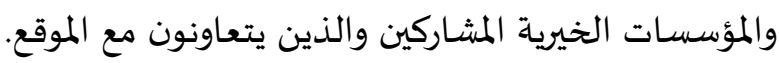
ويحتوي موقع الإسلام اليوم على قائمة من النوافذ المنوعة، والتي روعي فيها التكامل وتلبية الحاجات المختلفة للمستخدم ومن أهم هذه النوافذ:

مقالات: وهي نافذة تقوم على استضافة عدد من الكُتَّاب، الذين يقومون على مناقشة عدد مند من القضايا الفكرية والمنهجية، بأسلوب موضوعي وهادف، وتعتبر من أكثر نوافذ الموقع تصفئحاً. الفتاوى: وهي نافذة تهتم باستقبال أسئلة المتصفح بالعديد من المسائل الشرعية، والفتاوى التي يجيب عليه عنديها عدد من أصحاب الفضيلة العلماء. الصوتيات: وهي عبارة عن الدروس والمحاضرات المتنوعة التي تعطى أكثر من موضوع في التربية يتم إنزالها في الموقع بالصوت. بحوث ودراسات: تقديم مجموعة من الندوات البحثية، والدراسات العلمية، والرسائل الجامعية، يتم اختيارها من قبل المختصين في هذا المجال. بيت الأسرة: وهي نافذة تهتم بشؤون الأسرة والمرأة كما وتهتم بأمور البيت المسلم، وتقدم العديد من البرامج والتوجيهات التربوية. 
الاستشارات: وتختص هذه النافذة بمعالجة المشكلات التربوية، والاجتماعية، والنفسية، من رؤية إسلامية،

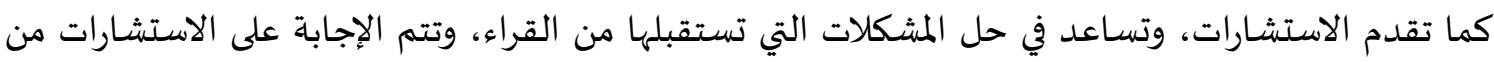
قبل مختصين في مختلف المجالات. المسلمون حول العالم: تقوم هذه النافذة بإلقاء الضيوء على أوضاع المسلمين في كافة انحاء العالم وأبرز مشاكلهم. القسم الإنجليزي: وتحتوي هذه النافذة على أول موسوعة مبسطة للإسلام، ثم تحريرها، وترجمتها، ومراجعتها،

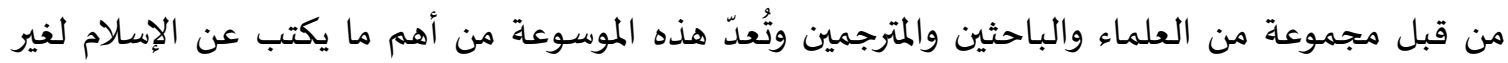

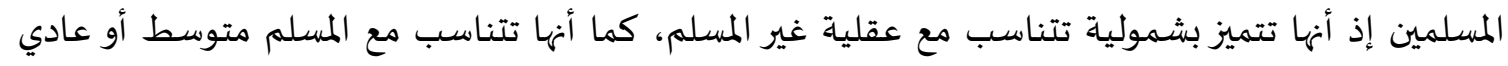
الثقافة لسهولة عباراتها وبعدها عن التقصير. القسم الفني: يعتبر القسم الفني لموقع الإسلام اليوم الحصن المنيع، والحارس الأمين، فهو الدعامة الرئيسية

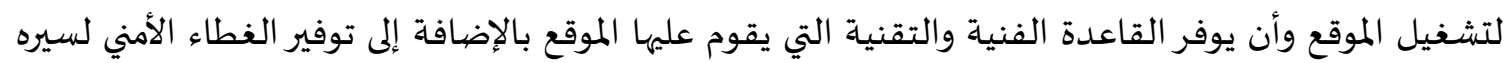

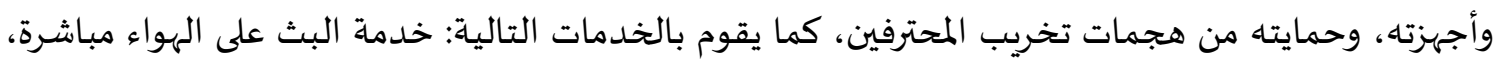

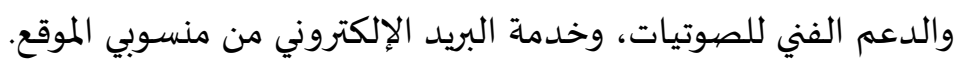

تحليل موقع الإسلام اليوم من حيث المضيمون: بعد تحليل كافة محتويات الموقع نرى بأنهُ يتضمن موضوعات الإنوات دينية متنوعة مصنفة إلى نوافذ وأبواب كما أهتم الموقع بالفتوى، حيث تم تخصيص لها "نافذة الفتاوى" وجعلت لها إدارة علمية خاصة، انطلقت من

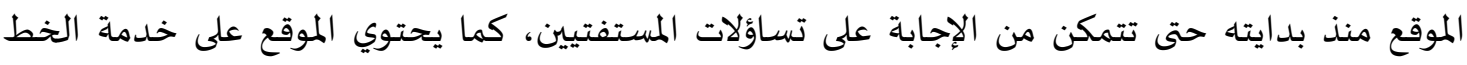

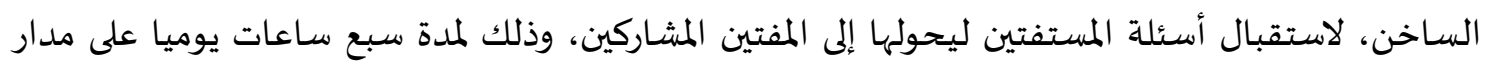
الأسبوع، ويشارك في هذه الخدمة مجموعة من العلماء والقضاء، وأساتذة الجامعات، كما تقوم الإدارة العلمية بنشر البحوث العلمية للمتخصصين الشرعيين والتعريف بنتاجهم وتقوية التواصل بينهم.

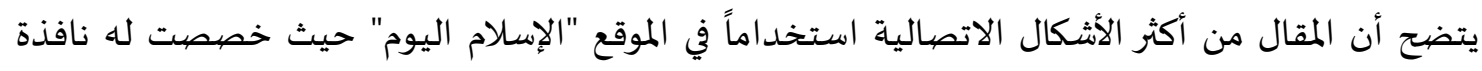

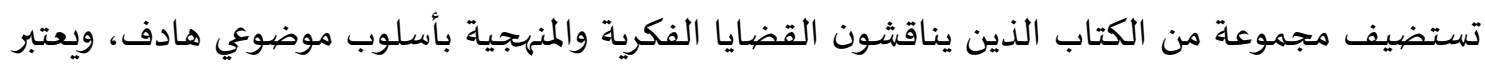

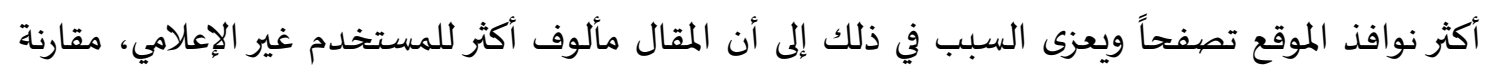

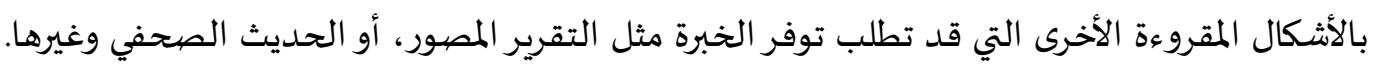

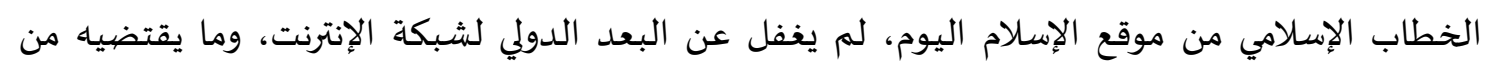

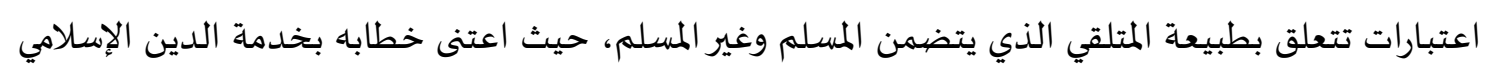

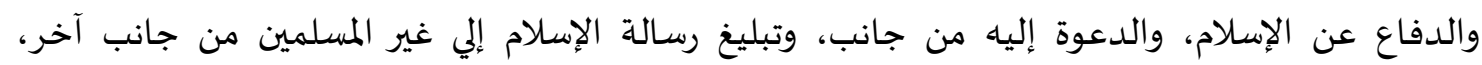

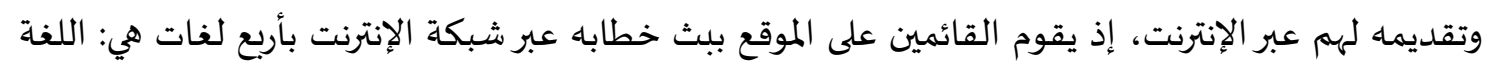

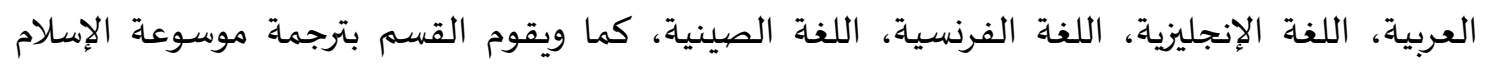
المبسطة. تضمن الموقع موضوعات تتعلق بشؤون الأسرة وخصص لها أبواب لهذه الغرض مثل (بيت الأسرة) وهي

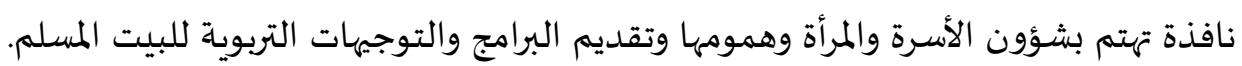


حرص الموقع على الاهتمام بتقديم القرآن الكريم، والسنة النبوية والسيرة المطهرة، كذلك اهتم الموقع بموضوعات عامة لترسيخ العقيدة الإسلامية.

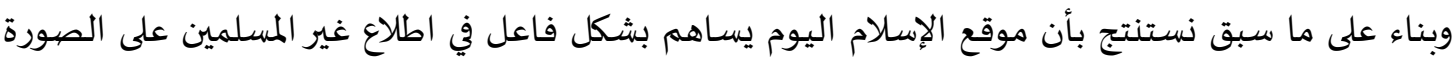
الحقيقية للإسلام بطريقة مبسطة وسهلة. كما ويسهم موقع الإسلام اليوم في إيجاد صورة وانطباعات إيجابية نحو

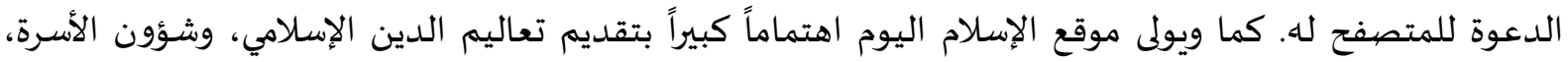

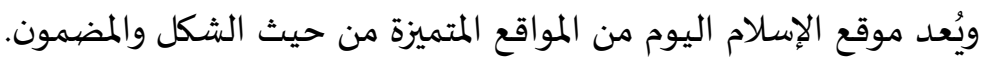

الفرع الثاني: موقع المفكرة الدعوية: وهو موقع دعوي متميز، ويتوفر باللغتين العربية والإنجليزية ويعمل على نشر الدعوة الإسلامية، ويقدم موقع

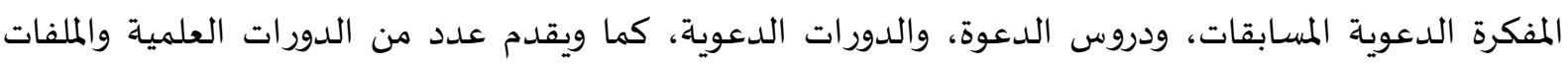
الدعوية، وبرامج المسابقات، بالإضافة إلى الاستشارات الدعوية، ورابط الدليل الدعوي، والباتهاحث الإسلامي، والمراكز

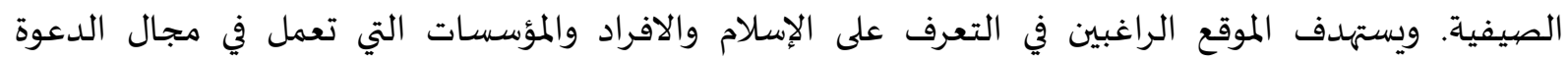

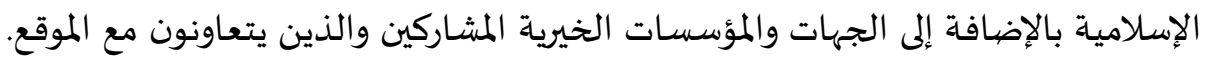

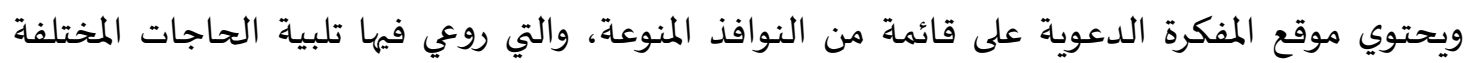

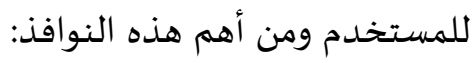
الصفحة الرئيسية: وتحتوي على نوافذ لأقسام الموقع، وأخر المستجدات الدعوية، بالإضافة إلى شريط يحتوي

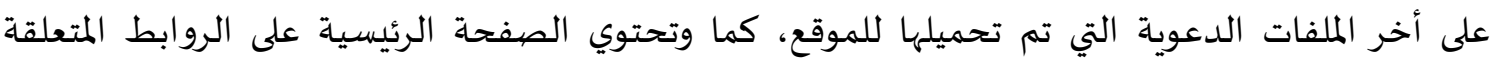

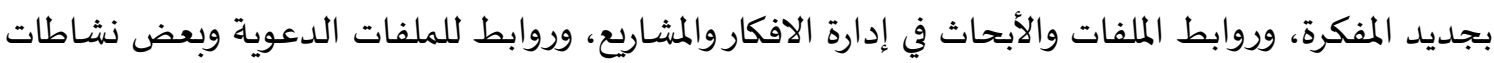

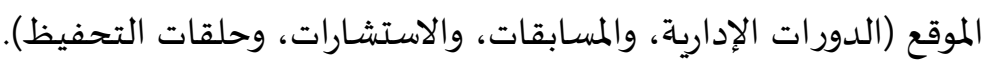

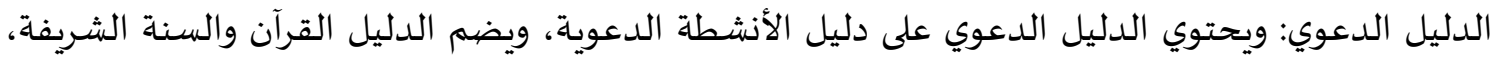

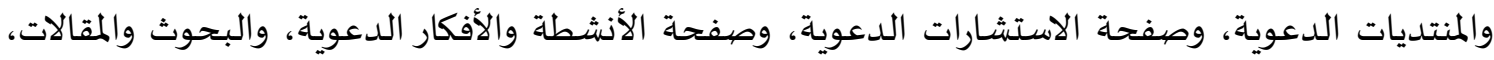

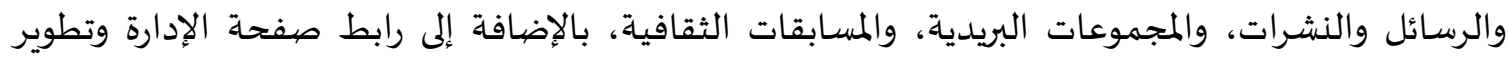
الذات، ورابط صفحة صهوتيات وبث مباشر. حلقات: وتضم موسوعة حلقات تحفيظ القرآن الكريم، وتتضمن بحوث تحفيظ القرآن الكريم، وبحوث مؤتمر

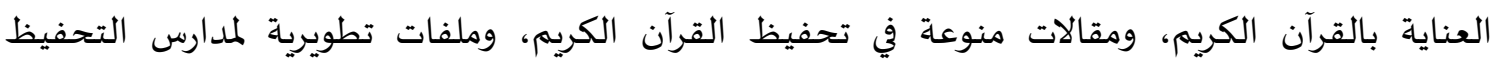

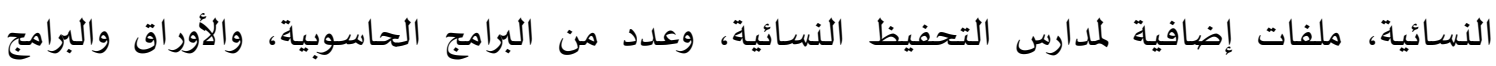

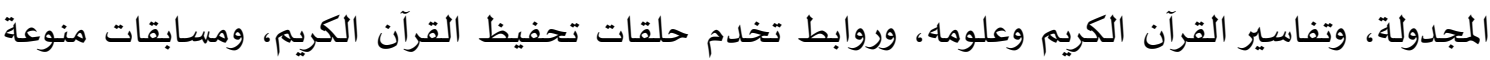

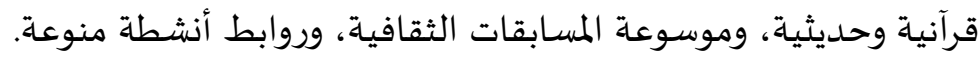
المكتبة: وتضهم مكتبة السير والقصص للعظماء والمبدعين والقادة، وكتب عن سيرة النبي صل الله عليه وسلم،

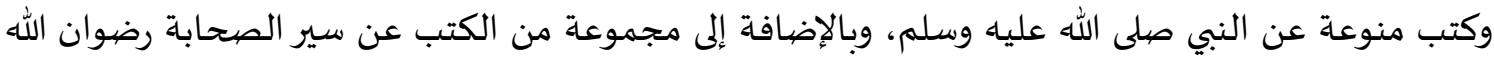

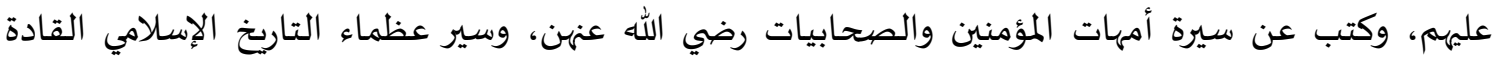
والعلماء والقدوات، وكتب عن قصص عظيمات ونساء الأمة، وكتب سير العلماء في العصر الحديث، ووالقصص الممتع والمفيد، ومكتبة الكتب العلمية والاعجاز القرآني، وكتب الدعوة والتربية. البحث: وتضم البحوث الدعوية والشرعياة. المسابقات: وتضم موسوعة المسابقات الثقافية. 
مختارات: وتضيم النافذة صفحات مختارة من الإنترنت تتعلق بالدعوة الإسلامية. مسكي - ويب: وهي عبارة عن منصة المواد التطويرية والتربوية وتضهم عدد من البرامج التربوية. بالإضافة إلى نافذة (Dawah_Training) باللغة الانجليزية، والتي يتم من خلالها التعلم على مهارات الاتصال منهال الحواري للدعوة باللغة الإنجليزية الإسلامية. كما ويحتوي موقع المفكرة الدعوية على قائمة من اقسام الموقع، والتي روعي فيها تلبية الحاجات المختلفة

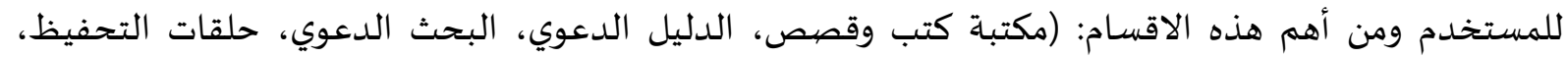

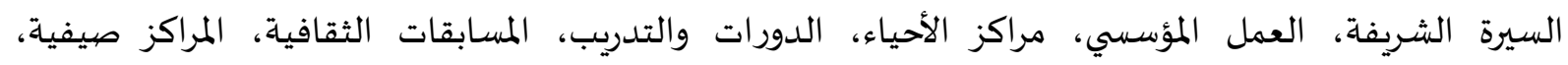
حاسوبيات، نشرات، صفحات مختارة)

تحليل موقع المفكرة الدعوية من حيث المضهمون: بعد تحليل كافة محتويات الموقع نرى بأنهُ يتضمن موضوعات المونات دينية متنوعة مصنفة إلى نوافذ وأبواب كما

اهتم الموقع بالفتوى، حيث تم تخصيص لها "نافذة الفتاوى" وجعلت لها إدارة علمية خاصة،، انطلقت من

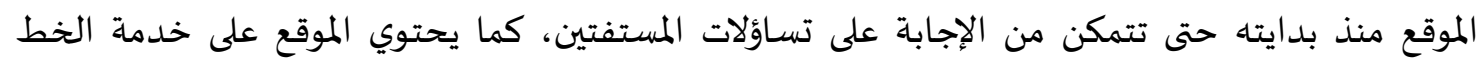

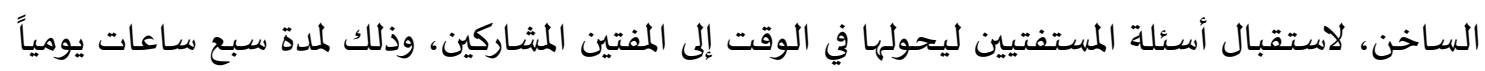

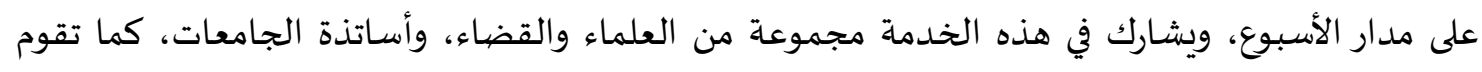
الإدارة العلمية بنشر البحوث العلمية للمتخصصين الشرعيين والتعريف بنتاجههم وتقوية التواصل بـاهل بينهم.

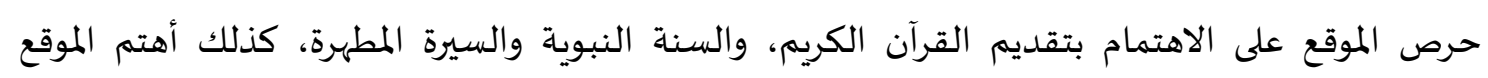
بموضوعات دعامة لترسيخ العقيدة الإسلامية.

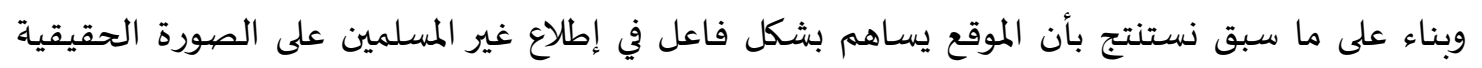

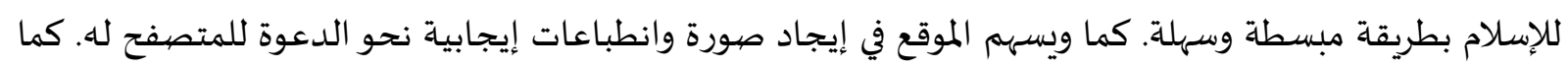

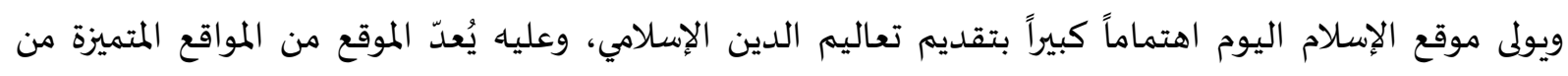
حيث الشكل والمضمون.

الفرع الثالث: موقع دار السلام للدعوة الإسلامية: يهدف الموقع إلى إيجاد مرجعية علمية مجانية على شبكة الإنترنت من أجل التعريف بالإسلام لغير المسلمين

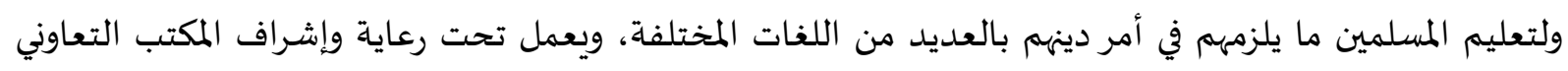
للدعوة وتوعية الجاليات بالربوة في مدينة الرياض، ويتكون الموقع من سلسلة من المواقع العملاقية الموثوثوقة

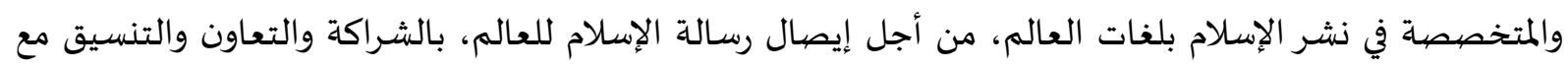

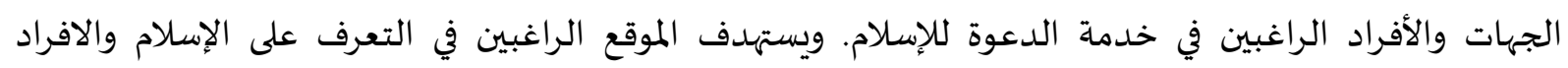

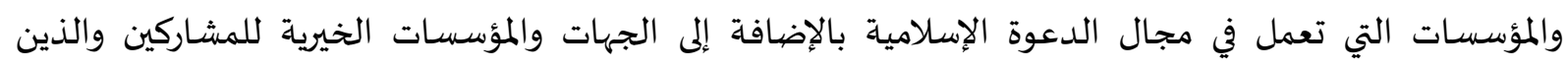

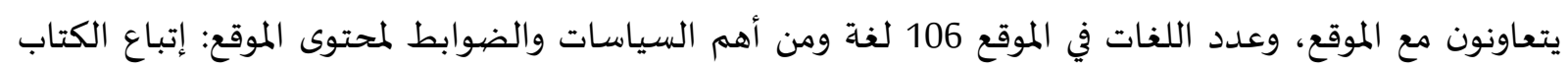

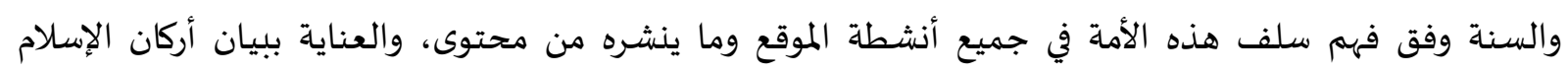

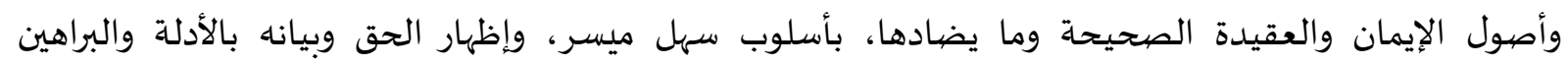


للباحثين والراغبين في معرفة الصواب، وبيان أصول الدين وفروعه ودعوة الناس إلى التمسك بها، وتجنب إثارة

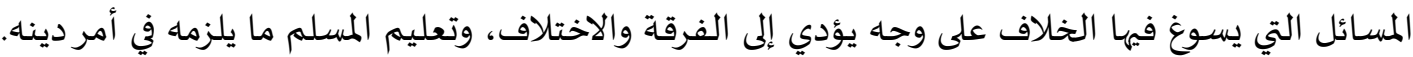
ويحتوي موقع دار السلام للدعوة الإسلامية على قائمة من النوافذ المنوعة، والتي روعي فهها التكامل وتلبية الحاجات المختلفة للمستخدم ومن أهم هذه النوافذ:

الرئيسية: وتحتوي على نوافذ لأقسام الموقع، واخر المستجدات الدعوية، بالإضافة إلى شريط يحتوي على

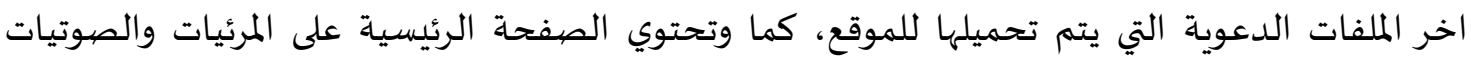
والكتب والتطبيقات الإسلامية التابعة للموقع. الصوتيات والمرئيات: وهي عبارة عن الدروس والمحاضرات المتنوعة التي تعطى أكثر من موضهوع في التربية يته إنزالها في الموقع بالصوت، كما وتحتوي على شرح صحيح مسلم وصحيح بخاري واذكار ونار الصباح والمساء. التطبيقات الإسلامية: وهي مجموعاة من التطبيقات التي تهم المسلمين كأذكار الصباح والمساء وغيرها من التطبيقات التي يستطيع المستخدم تنزليها والاستفادة منها. جميع المواد: وتضهم القرآن الكريم ومكتبة تحتوي على العديد من الكتب التي تتعلق بسيرة النبي صلى الله

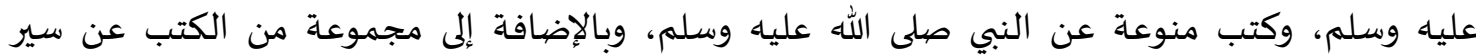

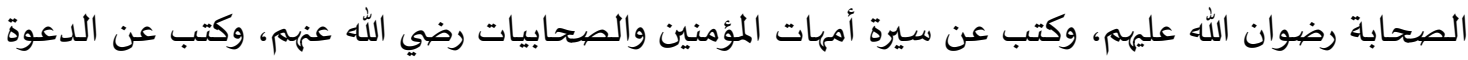

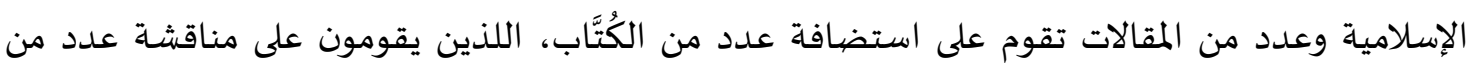
القضايا الفكرية والمنهجية، بأسلوب موضوعي وهادف، وتعتبر من أكثر نوافذ الموقع تصفحا. الانضمام إلى الإسلام: وتهدف هذه النافذة إلى التعريف كيف يتم الانضمام إلى الإسلام وتحتوي على عدد من

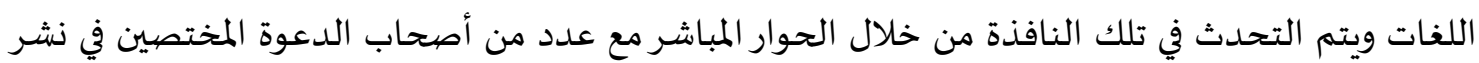

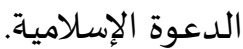
المزيد: وتتضمن تلك النافذة التعريف على عدد من أصحاب الدعوة الإسلامية، بالإضافة إلى المصادر والتي

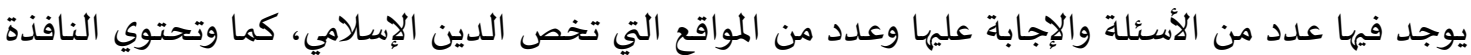
على عدد من المناهج التعليمية التي تهدف إلى التعريف بالإسلام. موسوعة القرآن الكريم والتي تحتوي على ترجمة للقرآن الكريم بأكثر من لغة حتى يسهل تعليمه باللغات المختلفة.

\section{تحليل موقع دار السلام للدعوة الإسلامية من حيث المضيمون:}

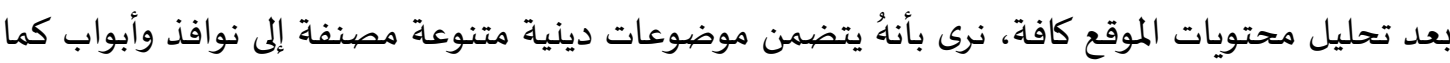

اهتم الموقع بالتطبيقات الإسلامية حيث تم تخصيص نافذة لتلك التطبيقات وجعلت لها إدارة علمية خاصة، انطلقت من الموقع منذ بدايته حتى تتمكن من مساعدة المسلمين على تنزيل التطبيقات التي تهمههم، تهات

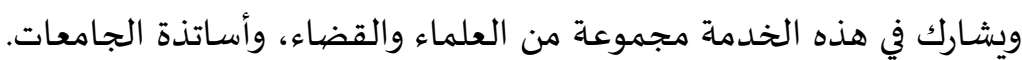
اهتم الموقع بالتعريف على عدد من أصحاب الدعوة الإسلامية، بالإضافة إلى المصادر والتي يوجد فيها عدد

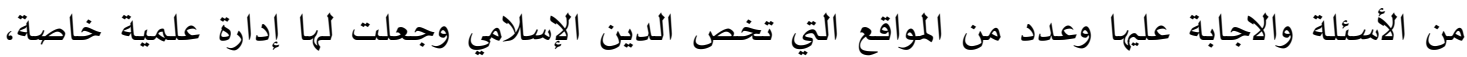
انطلقت من الموقع منذ بدايته حتى تتمكن من الإجابة على تساؤلات المستفتين والمسلمين وغير المسلمين، كما

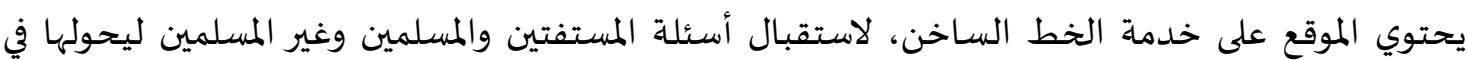


نفس الوقت إلى المفتين المشاركين، وذلك لمدة سبع ساعات يوميا على مدار الأسبوع، ويشارك في هذه الخدمة مجموعة من العلماء والقضاء، وأساتذة الجامعات، كما تقوم الإدارة العلمية بنشر البحوث العلمية للمتخصصين الشرعيين والتعريف بنتاجهم وتقوية التواصل بينهم،، كما وتحتوي النافذة على عدد من الن النهاء المناهج التعليمية التي تهدف إلى التعريف بالإسلام. أهتم الموقع بترجمة القرآن الكريم وكتب السنة النبوية والعديد من الكتب التي تهدف إلى التعريف بالإسلام بشكل مبسط ويسهل على الجميع استخدامها. أهتم الموقع بكيفية دعوة غير المسلمين للانضمام إلى الإسلام: من خلال الحوار المباشر مع عدد من أصحاب الصاب الدعوة المختصين في نشر الدعوة الإسلامية. وبناء على ما سبق نستنتج بأن موقع دار السلام للدعوة الإسلامية يساهم بشكل فاعل في إطلاع غير المسلمين على الصورة الحقيقية للإسلام بطريقة مبسطة وسهلة. كما ويسهم موقع الإسلام اليوم في إيجاد صورة

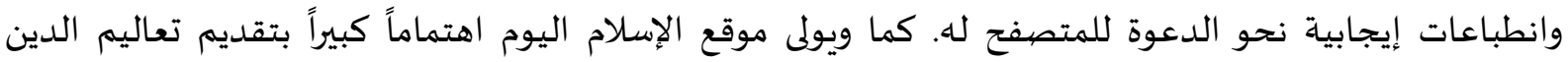

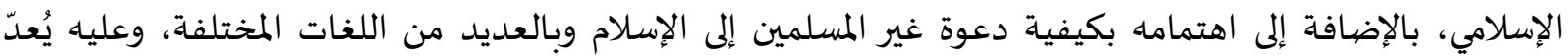

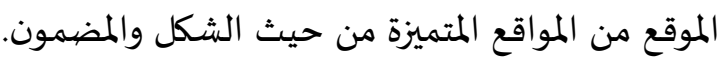

ثانياً: تحليل استبانة البحث بعد القيام بعملية جمع البيانات تم معالجة هذه البيانات إحصائياً من خلال استخدام براندان برنامج الرزمة الإحصائية للعلوم الاجتماعية (SPSS)، وفيما يلي عرض لأهم النتائج التي تم توصل إنيات إليها:

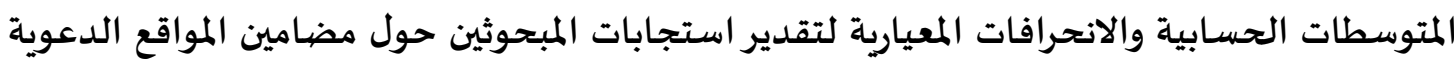
الإسلامية (موقع الإسلام اليوم، وموقع المفكرة الدعوية، وموقع دار السلام للدعوة الإسلامية) على شبكة التحونة

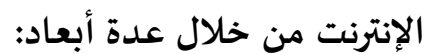
يبين الجدول رقم (2): معيار تقدير استجابات المبحوثين حول مضامين المواقع الدعوية الإسلامية (موقع

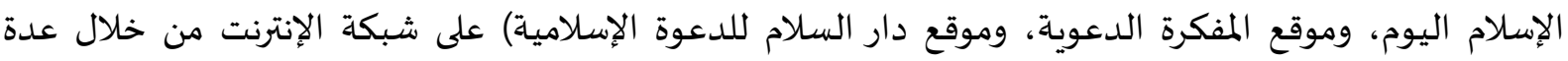

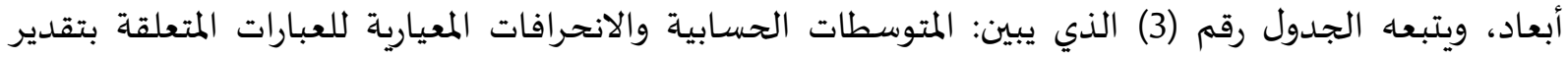

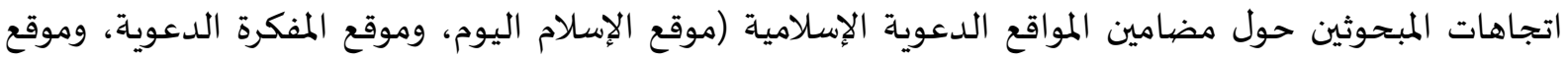
دار السلام للدعوة الإسلامية) على شبكة الإنترنت من خلال عدة أبعاد.

جدول رقم (2): معيار تقدير استجابات المبحوثين لمستوى استجاباتهم حول مضيامين المواقع الدعوية الإسلامية

\begin{tabular}{|c|c|}
\hline تقدير توافق أفراد العينة & المتوسط الحسابي \\
\hline ضعيفة & $2.33-1$ \\
\hline جيدة إ & $3.66-2.34$ \\
\hline قوية ق & $5-3.67$ \\
\hline
\end{tabular}

وفي إطار معرفة تقدير استجابات المبحوثين حول مضامين المواقع الدعوية الإسلامية؛ جاءت النتائج كما في

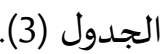


جدول (3): المتوسطات الحسابية والانحرافات المعيارية للعبارات المتعلقة استجابات الجمههور حول محتوى المواقع الدعوية الإسلامية (موقع الإسلام اليوم، وموقع المفكرة الدعوية، وموقع دار السلام للدعوة الإسلامية) على شبكة الإنترنت

\begin{tabular}{|c|c|c|c|}
\hline 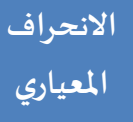 & \multicolumn{2}{|l|}{ الحسبط المتوسط } & $\hat{\imath}$ \\
\hline \multicolumn{4}{|c|}{ البعد الأول: مدى وضهوح الأهداف التي تستخدمها المواقع الدعوية عبر الإنترنت } \\
\hline 0.504 & 4.49 & 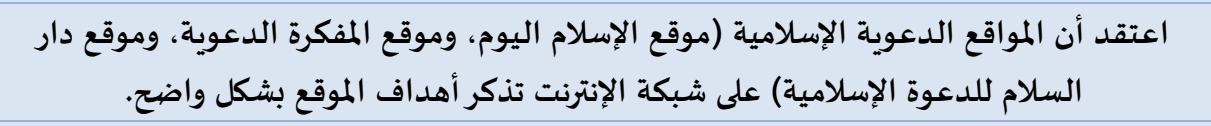 & 1 \\
\hline 0.434 & 4.75 & 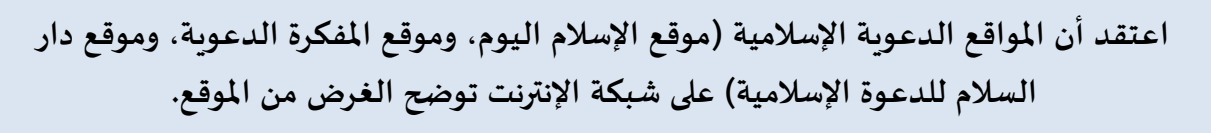 & 2 \\
\hline 0.598 & 4.23 & 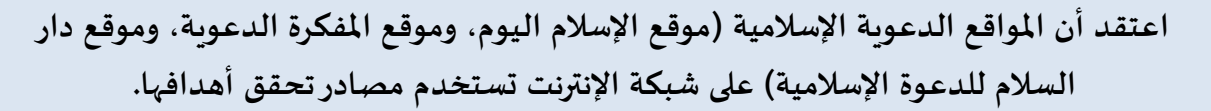 & 3 \\
\hline 0.426 & 4.12 & 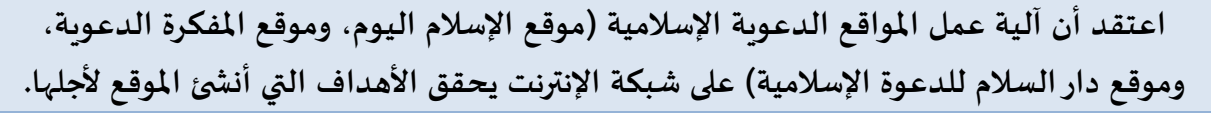 & 4 \\
\hline 0.490 & 4.39 & الدرجة الكلية لمدى وضهوح الأهداف التي تستخدمها المواقع الدعوية عبر الإنترنت & \\
\hline \multicolumn{4}{|c|}{ البُعد الثاني: آلية استخدام الأحاديث النبوية الشريفة في المواقع الدعوية عبر الإنترنت } \\
\hline 1.019 & 2.88 & 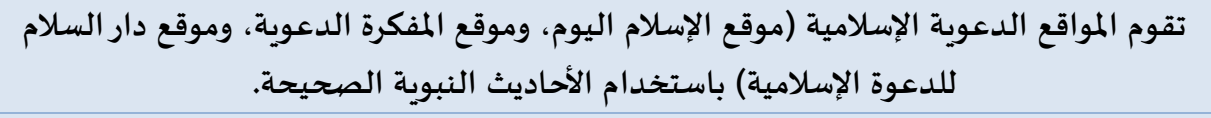 & 5 \\
\hline 1.001 & 3.12 & 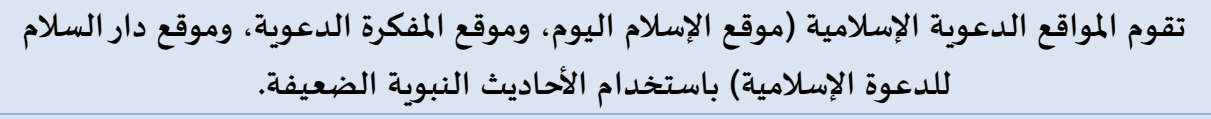 & 6 \\
\hline 0.921 & 3.61 & 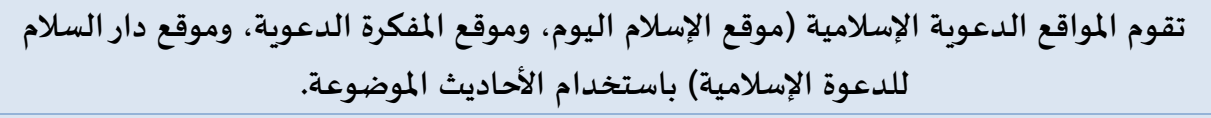 & 7 \\
\hline 0.900 & 3.66 & 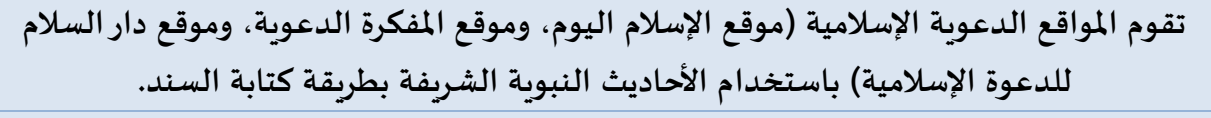 & 8 \\
\hline 0.821 & 3.70 & 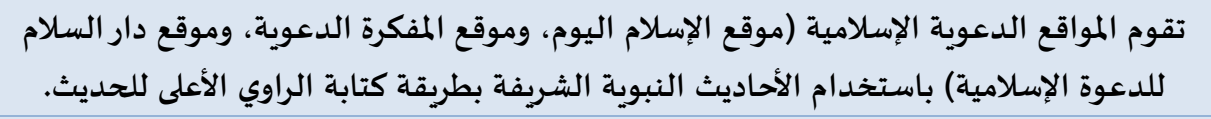 & 9 \\
\hline 0.932 & 3.39 & الدرجة الكلية لآلية استخدام الأحاديث النبوية الشريفة في المواقع الدعوية عبر الإنترنت & \\
\hline \multicolumn{4}{|c|}{ البعد الثالث: القيم التي تهتم بمعالجتها المواقع الدعوية عبر الإنترنت } \\
\hline 0.862 & 3.84 & 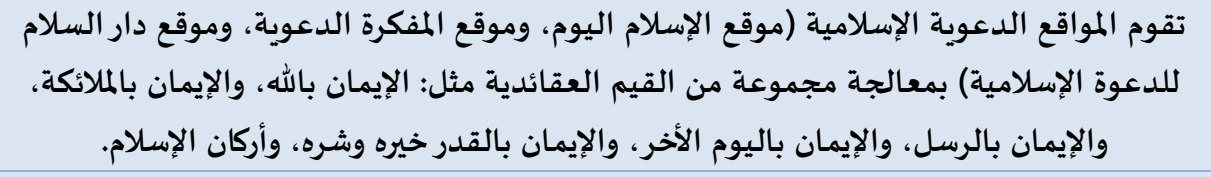 & 10 \\
\hline 1.001 & 3.12 & 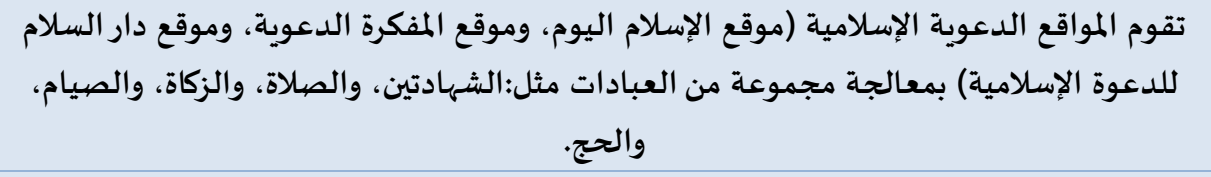 & 11 \\
\hline 0.426 & 4.12 & 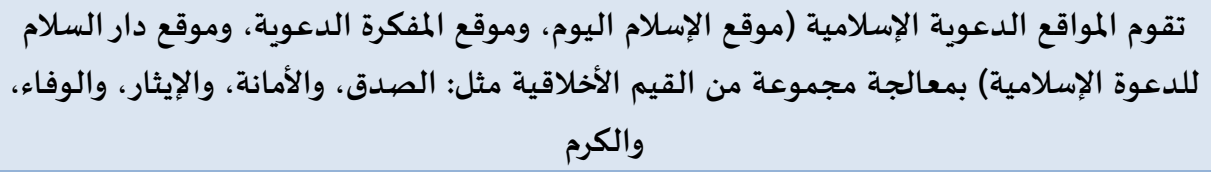 & 12 \\
\hline
\end{tabular}




\begin{tabular}{|c|c|c|c|}
\hline 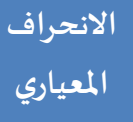 & الحستوسط & 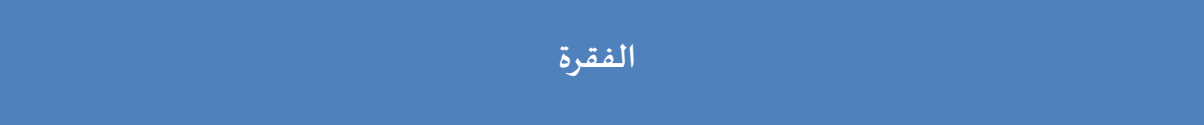 & $\hat{r}$ \\
\hline 1.013 & 3.21 & 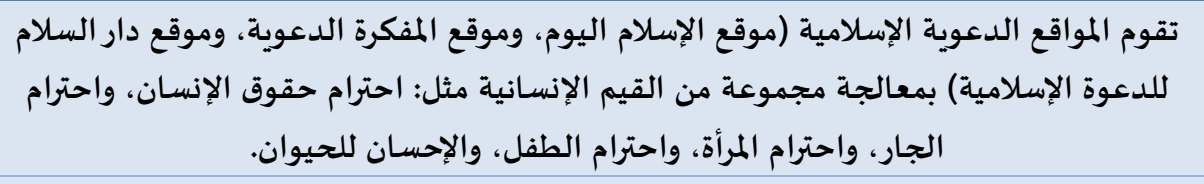 & 13 \\
\hline 0.825 & 3.57 & الدرجة الكلية للقيم التي تهتم بمعالجتها المواقع الدعوية عبر الإنترنت & \\
\hline \multicolumn{4}{|c|}{ البعد الرابع: الأساليب وطرق الاستدلال والفتاوى والموضهوعات التي تستخدمها المواقع الدعوية عبر الإنترنت } \\
\hline 1.035 & 3.23 & 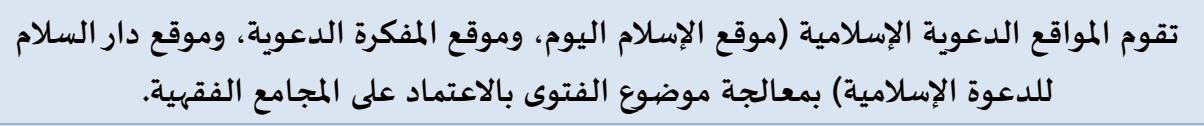 & 14 \\
\hline 1.001 & 3.12 & 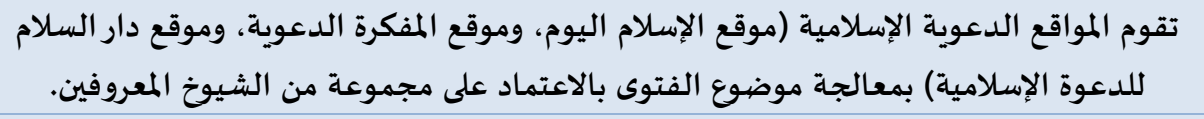 & 15 \\
\hline 0.755 & 2.42 & 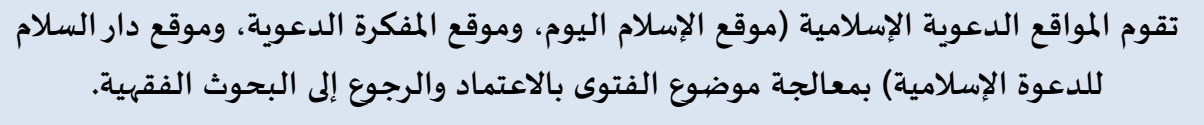 & 16 \\
\hline 0.426 & 4.12 & 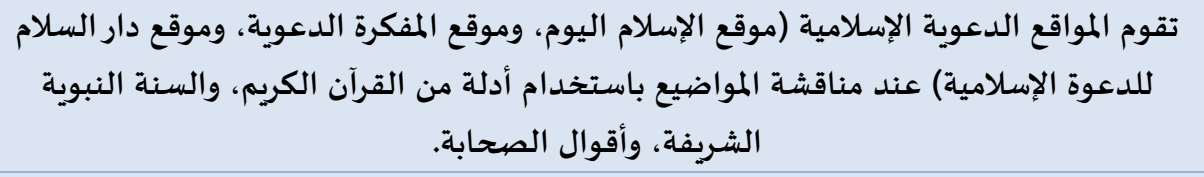 & 17 \\
\hline 0.708 & 2.23 & 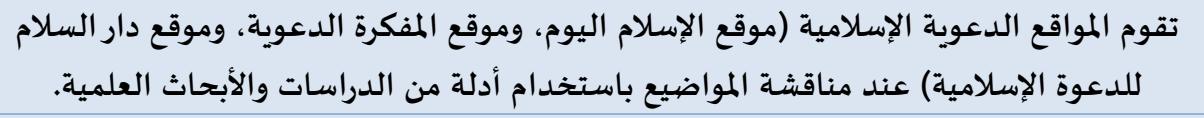 & 18 \\
\hline 0.537 & 4.54 & 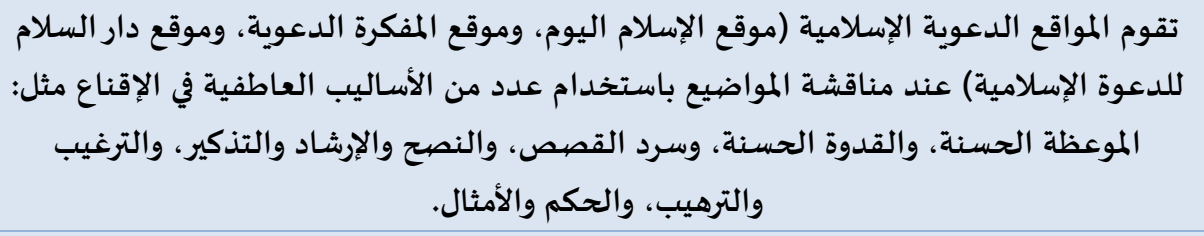 & 19 \\
\hline 0.785 & 3.02 & \multicolumn{2}{|l|}{ الدرجة الكلية للأساليب وطرق الاستدلال والفتاوى والموضوعات التي تستخدمها المواقع الدعوية عبر } \\
\hline 0.758 & 3.59 & \multicolumn{2}{|l|}{ الدرجة الكلية لمضشامين المواقع الدعوية الإسلامية عبر الإنترنت } \\
\hline
\end{tabular}

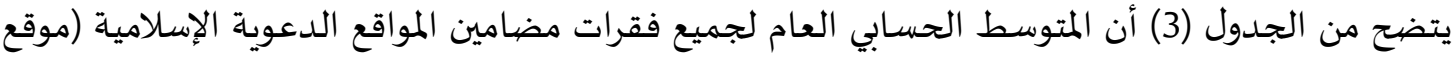
الإسلام اليوم، وموقع المفكرة الدعوية، وموقع دار السلام للدعوة الإسلامية) على شبكة الإنترنت قد بلغ المعام (3.59) وهي

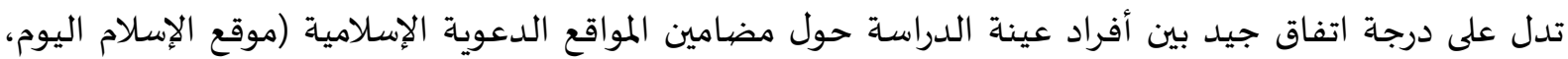

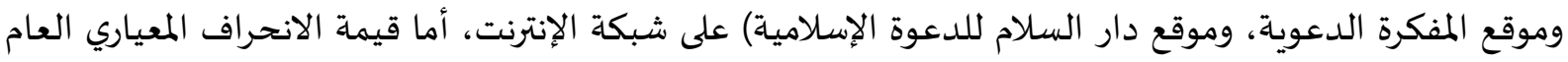
فقد بلغت (0.758) وهو أمر طبيعي يعكس التقارب في استجابات أفراد عينة الدراسة.

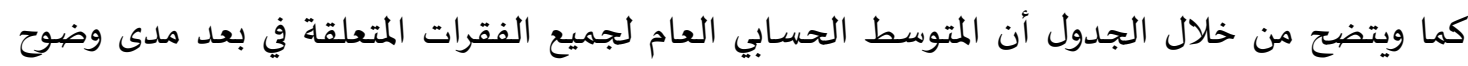

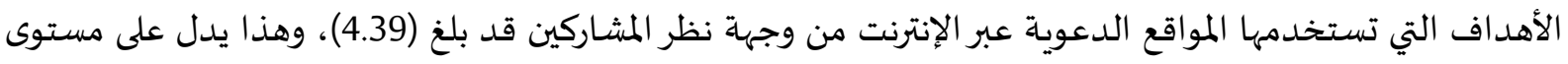

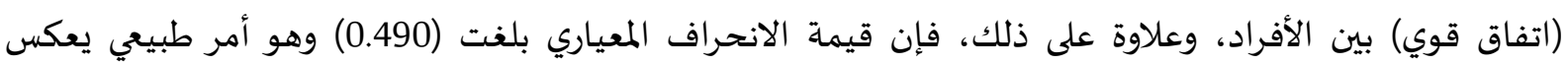

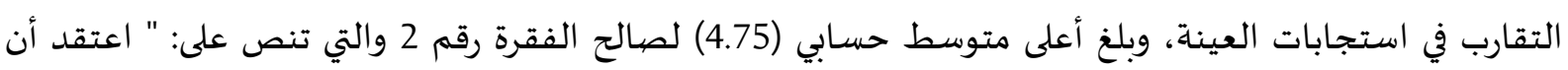

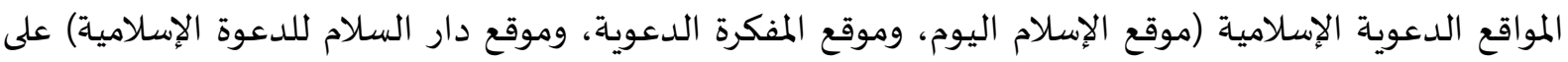

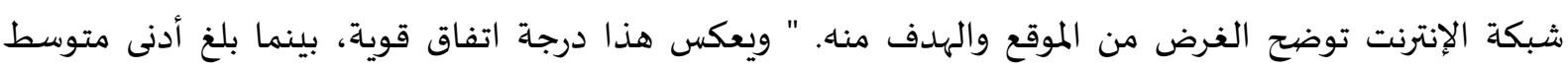
حسابي (4.12) لصالح الفقرة رقم 4 والتي تنص على: " اعتقد أن آلية عمل المواقع الدعوية الإسلامية (موقع الإسلام 
اليوم، وموقع المفكرة الدعوية، وموقع دار السلام للدعوة الإسلامية) على شبكة الإنترنت يحقق الأهداف التي أنشئ

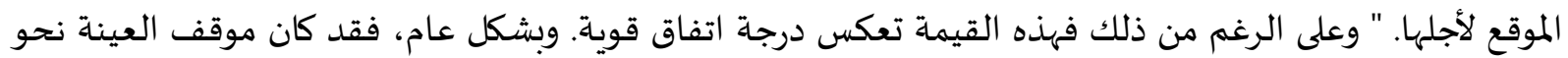

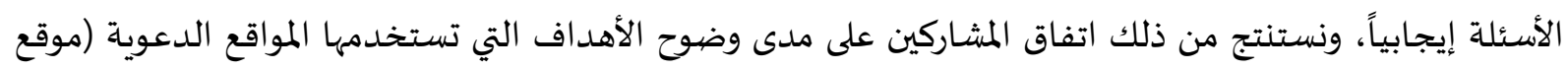

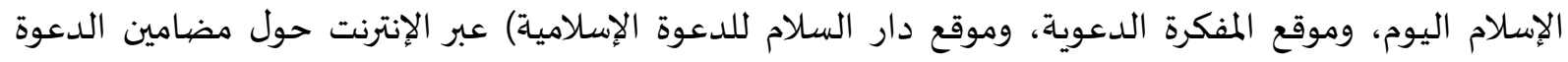

كما وناحظ من خلال الجدول السابق أن المتوسط الحسابي العام لجميع الفقرات المتعلقة في بعد آلية

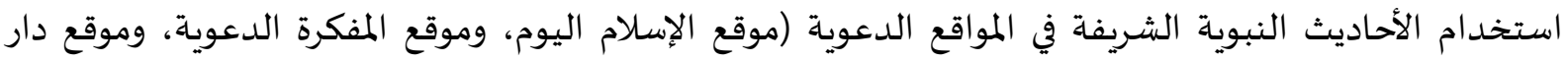

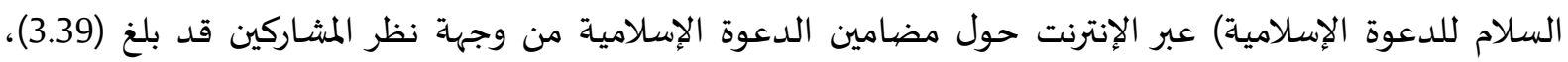

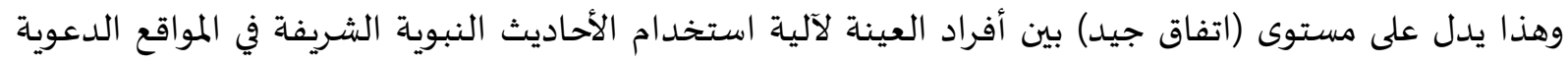

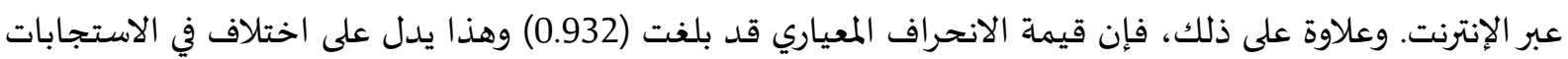

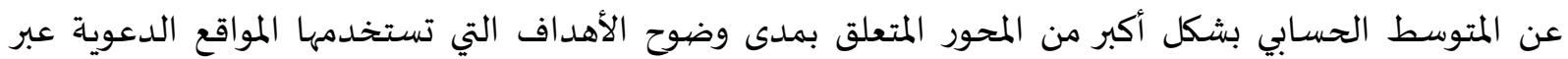

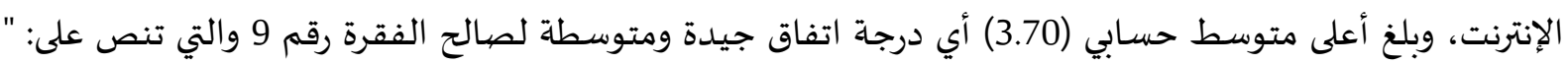
تقوم المواقع الدعوية الإسلامية (موقع الإسلام اليوم، وموقع المفكرة الدعوية، وموقع دار السلام للدعوة الإسلامية)

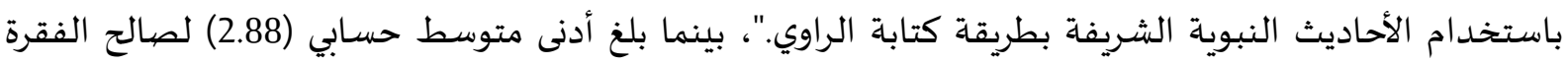

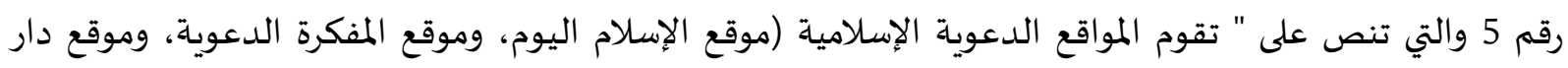

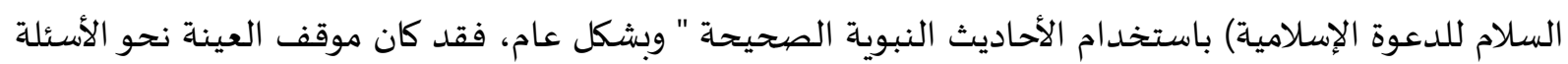
متفاوتاً.

إضافة إلى ذلك فإننا نلاحظ من خلال الجدول السابق أن المتوسط الحسابي العام لجميع الفقرات المتعلقة

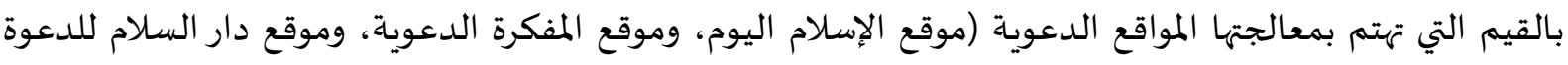

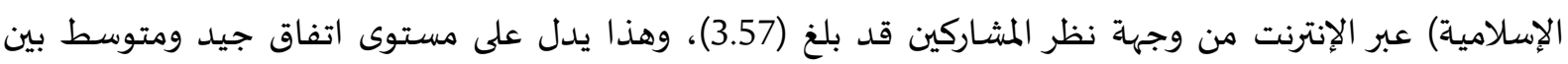

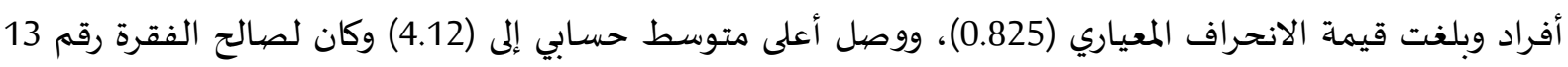

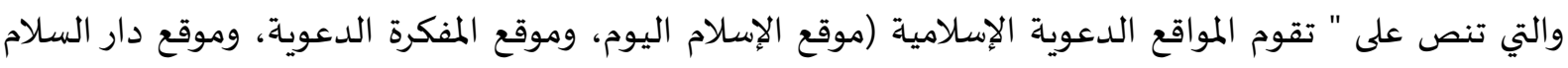

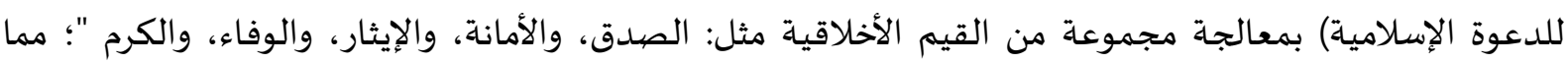

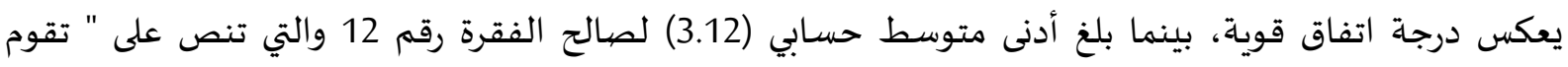

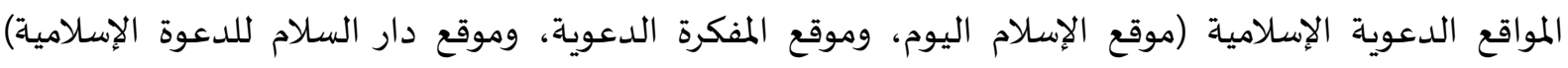

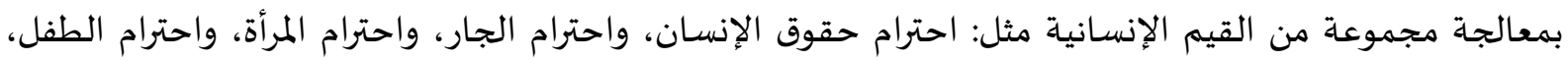
والإحسان للحيوان." وهذا يعكس درجة اتفاق جيدة. وبشكل عام، فقد كان موقف الفيم الإندانة العينة نحو الأسئلة إيجابياً،

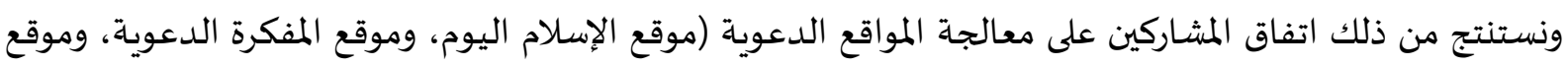

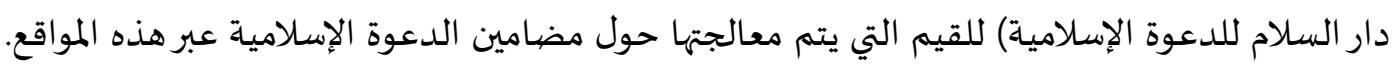

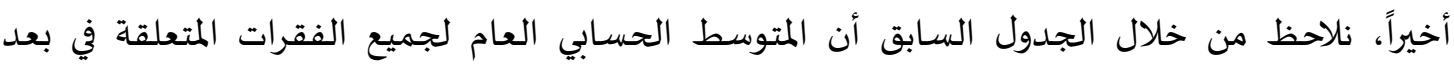

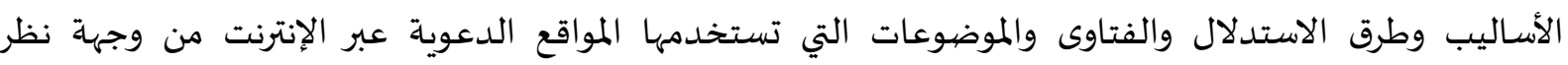

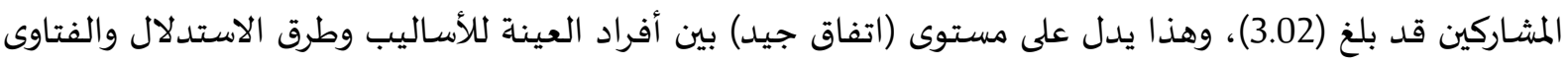

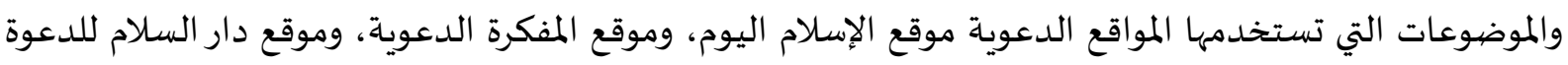

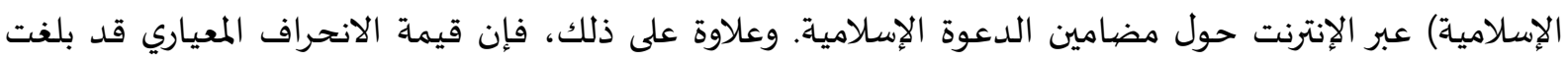

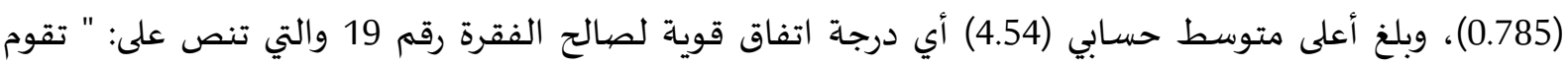


المواقع الدعوية الإسلامية (موقع الإسلام اليوم، وموقع المفكرة الدعوية، وموقع دار السلام للدعوة الإسلامية) عند

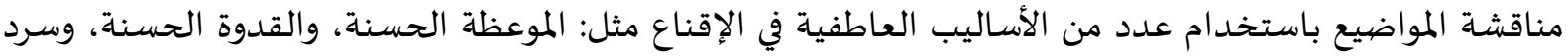

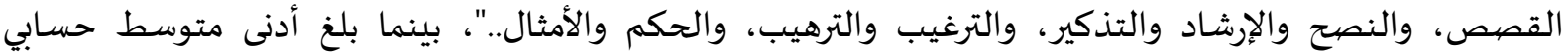

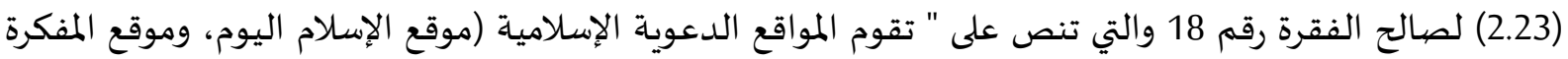
الدعوية، وموقع دار السلام للدعوة الإسلامية) عند مناقشة المواضيع باستخدام أدلة من الدراسات والأبحاث العلمية." وبشكل عام، فقد كان موقف العينة نحو الأسئلة متفاوتاً.

ملخص نتائج الدراسة

يتضمن هذا القسم ملخص لنتائج الدراسـة من خلال الإجابة على أسئلة الدراسة كما يلي:

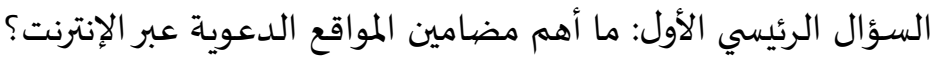

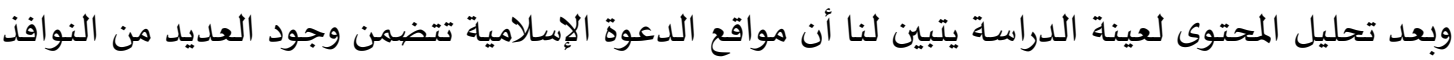
والمقالات والكتب التي تخدم الدعوة الإسلامية وتساهم بشكل فاعل في إطلاع غير المسلمين على صورة الإسلام وإيجاد صورة وانطباعات إيجابية نحو الدعوة للمتصفح له. كما وتهدف العديد من المواقع الدعوية على تقديم تعاليم الدين الإسلامي بشكل يسهل فهمه على غير المسلمين وعلى المسلمين الذين يرغبون بالتعليم بشكل أفضل عن المبان الدين الإسلامي ويرغبون في أخذ الفتاوى حول العديد من المواضيع التي تهمهم. وتؤكد نتائج تحليل الاستبانة ذلك إذ أشارئ ألمارت النتائج إلى أن مضامين المواقع الدعوية الإسلامية (موقع الإسلام اليوم، وموقع المفكرة الدعوية، وموقع دارئ دار السلام

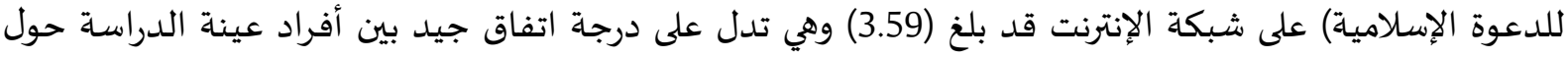
مضامين المواقع الدعوية الإسلامية (موقع الإسلام اليوم، وموقع المفكرة الدعوية، وموقع دار السلام للدعوة الإسلامية) على شبكة الإنترنت.

أما فيما يتعلق بنتائج الأسئلة الفرعية فيتضح لإنات لنا ما يلي: السؤال الفرعي الأول: ما أهم الأهداف التي تسعى المواقع الدعوية لتحقيقها؟

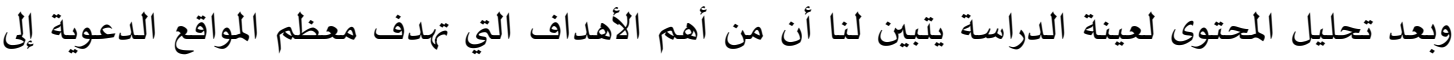

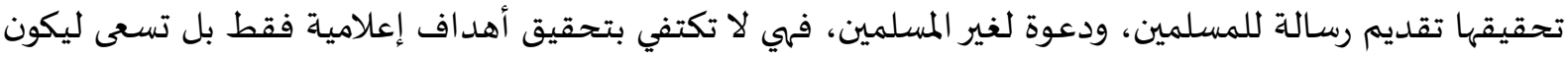
وسيلة من أجل ترسيخ العقيدة بطريقة صحيحة في قلوب المسلمين. كما وتهدف مواقع الدعوة الإسلامية إلى تقديم

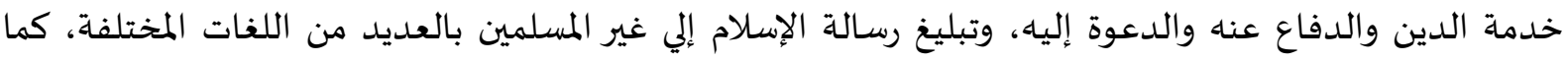
وتهدف بعض المواقع الدعوية إلى إيجاد مرجعية علمية مجانية على شبكة الإنترنت وذلك بهدف التعريف بالإسلام لغير المسلمين ولتعليم المسلمين ما يلزمهم في أمر دينهم باللغات المختلفة.

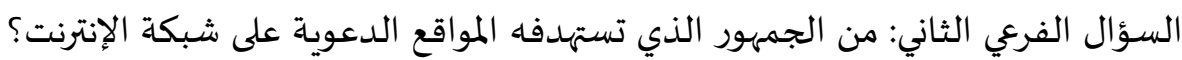

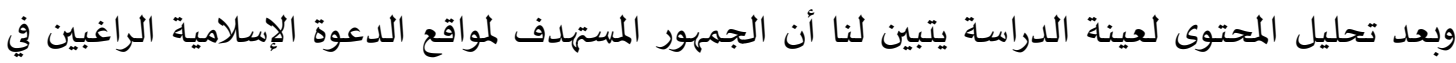
التعرف على الإسلام والمسلمين الذين يرغبون في التعرف أكثر على الإسلام والافراد والمؤسسات التي تعمل في مجال المعال

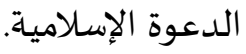

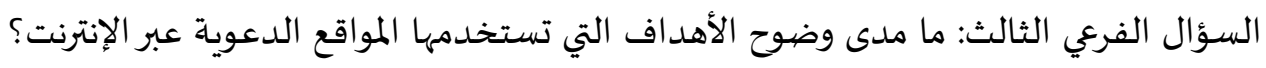

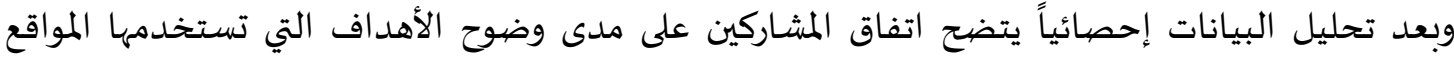

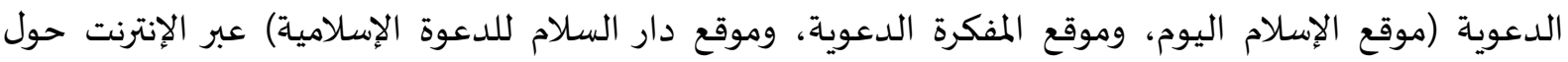


مضامين الدعوة الإسلامية، وذلك من خلال وضوح الغرض من الموقع والهدف منه، وبيان أهداف هذه المواقع بشكل واضح، وأن هذه الأهداف تقوم على تحقيق الأغراض التي تم إنشاء المواقع لأجلها.

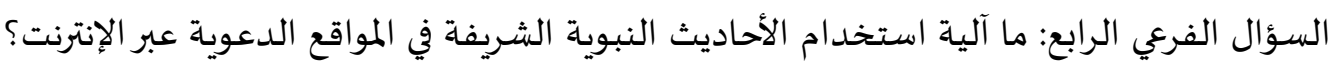

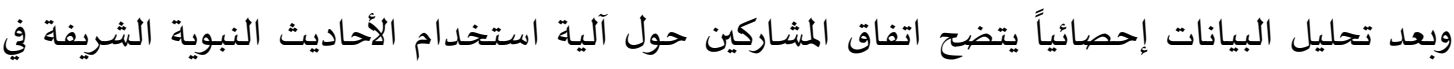

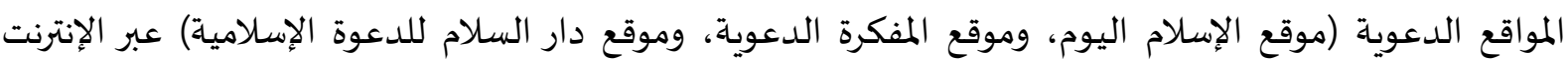

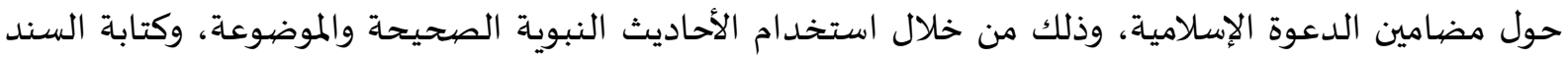
والراوي.

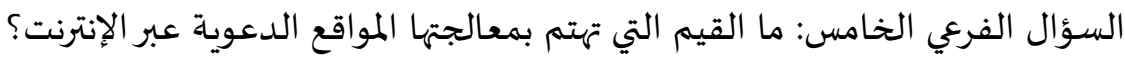

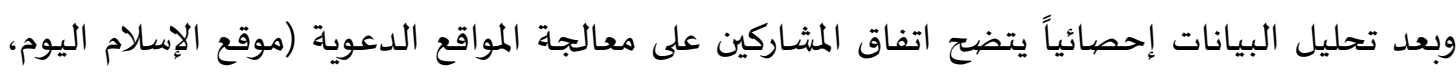

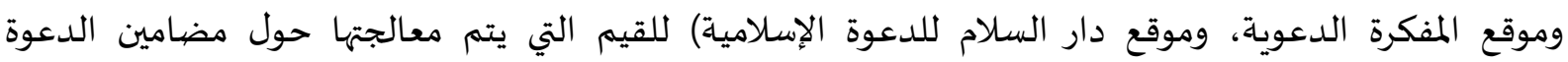

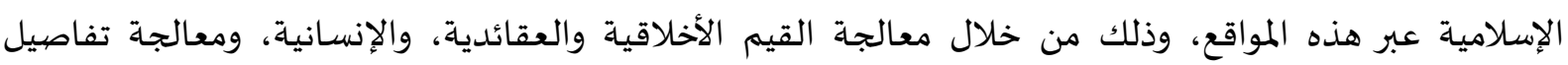

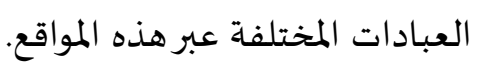

هالسؤال الفرعي السادس: ما الأساليب وطرق الاستدلال والفتاوى والموضوعات التي تستخدمها المواقع الدعوية

$$
\text { عبر الإنترنت؟ }
$$

وبعد تحليل البيانات إحصائياً يتضح اتفاق المشاركين على أهم الأساليب وطرق الاستدلال والفتاوى

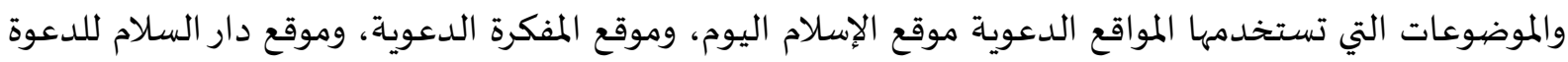

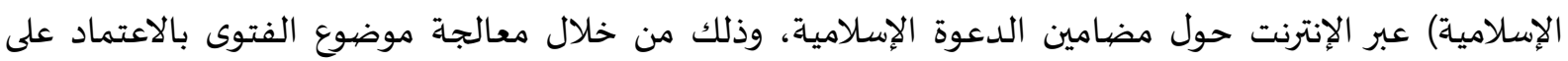

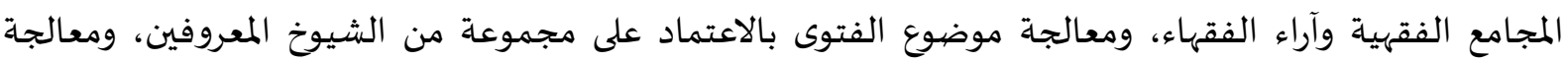

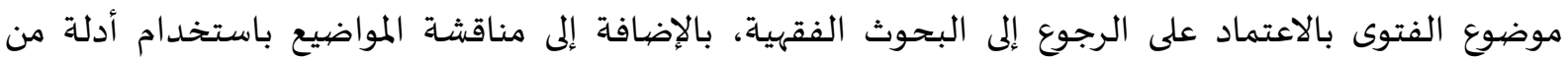

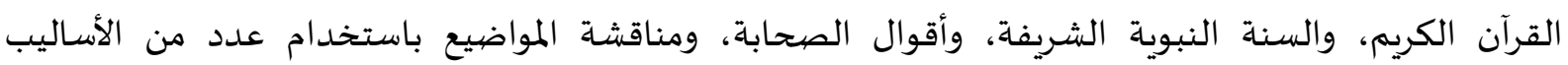

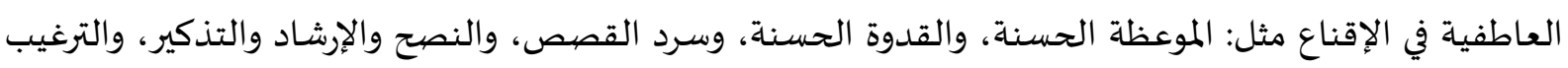

$$
\text { والترهيب، والحكم والأمثال. }
$$

بناء على نتائج الدراسة يوصي الباحث ويقترح بما يلي: ضرورة القيام بإنشاء مواقع إلكترونية مختلفة تقوم على التعريف بالإسلام وعلومه بكافة اللغات. ضرورة وضع العديد من الكتب المترجمة في مواقع الدعوة الإسلامية المختلفة للاستفادة منها في تبليغ الإسلام لغير الناطقين بالعربية. ضرورة استغلال شبكة الإنترنت بشكل أفضل من أجل الدعوة إلى الإسلام والتفكيرَ في العديد من الوسائل

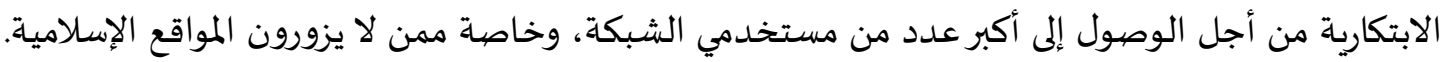


- أبو ضهير، فريد. (2012). استخدام طلبة الصحافة في جامعة النجاح الوطنية لشبكة الإنترنت والإشباعات المتحققة منها في تعزيز قدراتهم الصحفية. مجلة الجامعة الإسلامية للبحوث الإنسانية، المجلد 20، العدد واحد، ص ISSN 1726-6807http://www.iugaza.edu.ps/ar/periodical/.2012، 423- 489 - - الإمام الذهبي. (1996). سير أعلام النبلاء، تحقيق شعيب الأرناؤوط، الناشر: مؤسسة الرسالة بيروت.

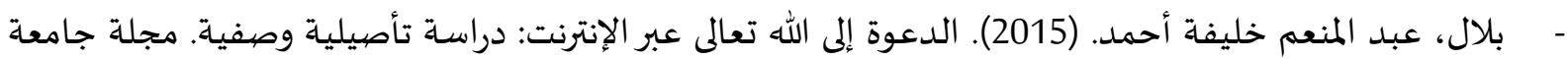
البطانة للعلوم الإنسانية والاجتماعية: جامعة البطانة - عمادة البحث العلمي والنشر والترجماة، 3 (1)، 293 -

- عبد الرازق، أسماء. (2015). الإنترنت: الفوائد والمخاطر. مجلة الخدمة الاجتماعية: الجمعية المصرية للأخصائيين الاجتماعيين، ع53، كارك، 219 - 237.

محمد، علي سعيد عثمان. (2013). موقع الإسلام اليوم Islam Today وإسهامه في الدعوة إلى الله. مجلة المنبر: هيئة علماء السودان، ع19، 196 - 1912.

محمد، علي. (2009). شبكة المعلومات الدولية الإنترنت والمواقع الدعوية بها واسهامها في الدعوة: نماذج مختارة (رسالة دكتور اه غير منشورة). جامعة أم درمان الإسلامية، أم درمان. المعان. محمد، عماد عيسي صالح. (2010). الاستخدامات المهنية لمواقع مشاركة الفيديو على شبكة الإنترنت يوتيوب You Tube نموذجا. اعلم: الاتحاد العربي للمكتبات والمعلومات، ع 6هم 6، 46 - 82.

ثانياً- المراجع بالإنجليزية:

- Aliyu, M., Mahmud, M., \& Tap, A. O. M. (2013). Features influencing Islamic websites use: A Muslim user perspective. Intellectual Discourse, 21 (1).

- Ismail, I., Ismail, M., \& Razak, F. H. A. (2013). A Website analysis on the use of multimedia elements for Islamic history content. In KSII the 5th International Conference on Internet (ICONI).

- Kort, A. (2005). Dar al-Cyber Islam: Women, domestic violence, and the Islamic reformation on the World Wide Web. Journal of Muslim Minority Affairs, 25 (3), 363-383.

- Shuriye, A. O., \& Ajala, M. T. (2014). Islam and the Cyber World. Journal of Educational and Social Research, 4 (6), 513. 